\title{
Biosensing Extracellular Vesicles: Contribution of Biomolecules in affinity-based methods for Detection and Isolation
}

\author{
M. Gaillarda,b, A. Thuaireb, G. Nonglaton ${ }^{\mathrm{b}}$, V. Agache ${ }^{\mathrm{b}, \mathrm{c}}$, Y. Roupioz ${ }^{\mathrm{a}}$ \& C. Raillon ${ }^{\mathrm{a}}$ \\ a Univ. Grenoble Alpes, CEA, CNRS, IRIG, SyMMES, 38000 Grenoble, France \\ ${ }^{b}$ Univ. Grenoble Alpes, CEA, LETI, Technologies for Healthcare and biology division, 38000 \\ Grenoble, France \\ ${ }^{c}$ David H. Koch Institute for Integrative Cancer Research, Massachusetts Institute of \\ Technology, Cambridge, MA 02142, USA
}

Correspondence and requests for materials should be addressed to C.R. (camille.raillon@cea.fr) or Y.R. (yoann.roupioz@cea.fr).

Keywords: Extracellular Vesicle, exosome, microvesicle, biosensing, detection, isolation, lab on a chip, antibody, DNA aptamer, peptide.

\begin{abstract}
Extracellular Vesicles (EVs) are lipid vesicles secreted by cells that allow intercellular communication. They are decorated by surface proteins, which are membrane proteins that can be targeted by biochemical techniques to isolate EVs from background particles. EVs have recently attracted attention for their potential applications as biomarkers for numerous diseases. This review focuses on the contribution of biomolecules used as ligands in affinity-based biosensors for the detection and isolation of EVs. Capturing biological objects like EVs with antibodies is well described in literature through different biosensing techniques. However, since handling proteins can be challenging due to stability issues, sensors using non-denaturable biomolecules are emerging. DNA aptamers, short DNA fragments that mimic antibody action, are currently being developed and considered as the future of antibody-like ligands. These molecules offer undeniable advantages: unparalleled ease of production, very high stability in air, similar affinity constants to antibodies, and compatibility with many organic solvents. The use of peptides specific to EVs is also an exciting biochemical solution to target EV membrane proteins and complement other probes. These different ligands have been used in several types of biosensors: electrochemical, optical, microfluidic using both generic probes (targeting widely expressed membrane proteins such as the tetraspanins) and specific probes (targeting disease biomarkers such as proteins overexpressed in cancer).
\end{abstract}




\section{Introduction}

\section{EVs basics}

Extracellular Vesicles (EVs) - which were initially considered to be undesirable debris are nanometric particles secreted by cells. Since the early 2000s, they have been the subject of increasing interest as their role in cell-cell communication and biological functions becomes more apparent. ${ }^{1-3}$ However, their discovery dates back to the 70s when they were first isolated from plasma. 4,5 Since then, they have been found in many bodily fluids including blood, urine, saliva, and milk ${ }^{6}$ as well as in animals, plants ${ }^{7}$ and culture media of cell lines. In recent years, the complexity of these nanometric objects has been revealed by several characterization methods, each one shedding light on another piece of the puzzle.

EVs are lipid vesicles that originate from parent cells and are often categorized by their excretion mechanism. When they bud from plasma membrane of cells they are known as microvesicles or large EVs, while multi-vesicular endosomes which fuse with the plasma membrane to release intraluminal vesicles are known as exosomes or small EVs, ${ }^{8,9}$ as shown in Figure 1. The size of large EVs ranges from $200 \mathrm{~nm}$ to $1 \mu \mathrm{m}$ in diameter, whereas small EVs are below $200 \mathrm{~nm}$. Moreover, biochemical composition of EVs can be quite different depending on their origin, fate and physiological role. ${ }^{6}$ They can carry a variety of biomolecules, ranging from nucleic acids - for example, DNA and microRNA - to proteins such as enzymes, signal transduction proteins and biogenesis factors. There are also surface-bound proteins on EVs, the most well-known being the tetraspanins (CD9, CD81, and CD63) which are widely expressed and thus very often targeted in bioaffinity assays. In addition, different types of lipids have also been found on EVs surfaces., ${ }^{2,10}$ Therefore, it is crucial to keep in mind the polydispersity and biochemical heterogeneity when working with EV samples.

\section{EVs as promising biomarkers for cancer applications}

EVs are promising biomarkers which could potentially be used for diagnostic applications to detect diseases at an early stage. Dedicated reviews have been published on the role of EVs in cancer progression and metastasis; where it is shown that EVs have a mediating effect on the tumor microenvironment promoting growth and invasiveness. ${ }^{1}$ Proteins that are already well known to be cancer markers such as Epithelial Cell Adhesion Molecules (EpCAM), Epidermal Growth Factor Receptor (EGFR) or Human Epidermal Receptor (HER) are demonstrated in the literature to be expressed on EV surface. ${ }^{11-13}$ Moreover, a very recent paper has identified surface proteins enriched in cancer-derived EVs compared to healthy tissue. ${ }^{14}$ The use of EVs derived from malignant cells as potential biomarkers of cancer is also well described in the literature. ${ }^{15-17}$ For example, Zhao et al. ${ }^{18}$ have published a detailed and recent review on this specific field showing the potential clinical application of EV and their role as cancer biomarkers. In their review, several works are listed on pancreatic cancer comparing their analytical 
performances and clinical utility, be it via EV cargo (DNA and miRNA) or surface biomarkers. Altogether, this strengthens the need for robust and reliable biosensing methods to detect and isolate EVs from bodily fluids.

\section{Current methods for detection and isolation}

Although recent papers published in the literature reinforce the central role of EVs in cellular signaling and their potential clinical use, their isolation and characterization still suffer from non-standardized experimental protocols. Such practical limitations have been pointed out during the annual meetings of the International Society on Extracellular Vesicles and a series of recommendations for the standardization of EV production and isolation have been proposed..$^{19,20}$

The current gold standard to purify EVs from cell cultures or bodily fluids is ultracentrifugation (UC). ${ }^{20,21}$ The aim is to eliminate larger and denser bodies (cells and cell debris) by differential centrifugation with a final $100000 \mathrm{~g}$ centrifugation step to separate EVs. To achieve better specificity, for instance if an EV subtype separation is needed, additional techniques following UC can be used. For example, Size-Exclusion Chromatography (SEC) or a sucrose gradient centrifugation can be coupled to UC for an optimal separation of EVs, especially from proteins aggregates.3,22-24 The purity of the EV fraction will depend on the application and the experimental question to be addressed. If the objective is the biochemical characterization of EVs, a highly purified and targeted EV fraction will be needed. On the other hand, to answer questions where the biochemical composition of EVs does not matter, high recovery rates and a low degree of specificity could be sufficient. Besides UC, several other isolation methods are available and some are listed below:

Density gradients and SEC. Like UC, density gradients and SEC are techniques that isolate EVs based on their physical properties (density and size). Because of their different densities, protein aggregates sediment whereas lipid vesicles float. In SEC, large particles will pass through the gel matrix faster than small particles and therefore will elute first. Both are non-destructive techniques and provide improved purity and recovery rates over UC.

Precipitation. Commercial kits based on EV precipitation have been developed such as ExoQuick $^{\mathrm{TM}}$ (System Biosciences), Exo-spin ${ }^{\mathrm{TM}}$ (Cell Guidance Systems) and Total Exosome Isolation (Invitrogen). Synthetic polymer-based precipitation uses additives that enable EV separation within 30 min which is less time-consuming than most UC protocols. However, the addition of reagents leads to concerns about the functional integrity of the recovered vesicles..$^{25,26}$

Filtration. Many commercially available filtration methods are based on sieving the sample through a nanoporous membrane. As for precipitation, current protocols are 
faster than UC but current standard operating procedures to avoid clogging are not yet optimized to achieve good yields.

Micro-/nano-based devices. The increase of integrated analysis platforms for EVs based on microfluidics, surface plasmon resonance, and electrochemistry (among others) is quite promising. As shown by Ko et al., ${ }^{27}$ a number of micro- and nano-technologies have already been developed to detect and isolate EVs, for example nanopores (TRPS), nanoholographic imaging or miniaturized nuclear magnetic resonance. More specific to microfluidic-based approaches, several designs have been developed such as herringbone grooves, ${ }^{17,28}$ circular chambers, ${ }^{29}$ or Deterministic Lateral Displacement (DLD). ${ }^{30,31}$ Microfluidic processing is a promising method to isolation EVs since they maintain their native morphology instead of being aggregated or fused by the high mechanical force of UC. However, most microfluidic chips are coupled with immunoaffinity 28 or filtration techniques ${ }^{32}$ and do not yet suffice as a stand-alone technology. Specific reviews on this subject have already been published. ${ }^{33}$ Such lab-on-a-chip platforms hold the promise of high sensitivity and high-throughput measurements.

Affinity-based approaches. The most common immunoaffinity-based method relies on the capture of EVs by antibody-coated magnetic beads. Vesicles displaying a transmembrane protein of interest will bind to beads and then be isolated by magnetic forces. The surface markers that are often targeted are the tetraspanin exosomal markers CD9, CD63, and CD81. Other affinity-based approaches have been developed using aptamers and peptides. The main advantage of affinity-based approaches is their specificity since it allows subpopulations of EVs to be isolated. However, when isolation from large quantities of biological sample is needed, we will see in this review that coupling affinity-based approaches to other techniques is essential.

\section{Downstream characterization methods}

Many microscopy techniques have been applied to the characterization of EVs. Scanning and Transmission Electron Microscopy (SEM, TEM) allows imaging of EVs ${ }^{21}$ at the nanometer resolution. In addition, cryo-TEM preserves the hydration state of biological samples and provides visual access to the lipid bilayer. Atomic Force Microscopy (AFM) has also been used to characterize EVs, ${ }^{34}$ and it allows to scan the sample surface under physiological conditions. Moreover, it can bring physico-chemical information about the EV membrane. The most widespread technique to measure size and concentration of EVs is an optical method based on the scattered intensity of a laser beam : Nanoparticle Tracking Analysis (NTA). Similarly, flow cytometry is also used to characterize EVs ${ }^{21}$ by measuring a fluorescently labeled bead-EV complex. There are also electrical sensing methods such as Tunable Resistive Pulse Sensing (TRPS) that are very accurate in terms of size information. ${ }^{35}$ Suspended Nanochannel Resonators (SNR) have also been used to characterize EVs, ${ }^{36}$ it is a mechanical technology based on flow-through weighing of nanoparticles. Evidently, many proteomic studies have been used to characterize the 
internal contents of EVs and classify them in database ${ }^{10,24,37,38}$ but this is outside the scope of our review.

Other reviews have been published on the subject, classifying isolation methods based on their physical principal (density, size or surface charge for example) ${ }^{39}$ or their application in cancer monitoring and diagnostics. ${ }^{27}$ In this Minireview, our focus is on affinity-based methods that target the biochemical surface composition of EVs. We will highlight original methods that target EVs based on their external composition; bringing forward the contribution of biomolecules in affinity-based methods for the detection and isolation of EVs. First, we will describe antibody affinity-based methods and group articles by device type. Second, we will focus on DNA affinity-based methods and finally, we will discuss emerging peptides probes for EV detection and isolation. This review is based on a database equation search which gathers recent papers, $80 \%$ of which were published in the last five years. Data was gathered with a Web of Science search using the following terms in 4 different categories: EVs (e.g. exosomes, microvesicles, extracellular vesicles) Sensors (e.g. biosensor, aptasensor, lab on chip); Manners (e.g. detection, isolation, analysis, immunoaffinity, characterization); and Biomolecules (e.g. antibody, DNA aptamer, oligonucleotide, peptide).

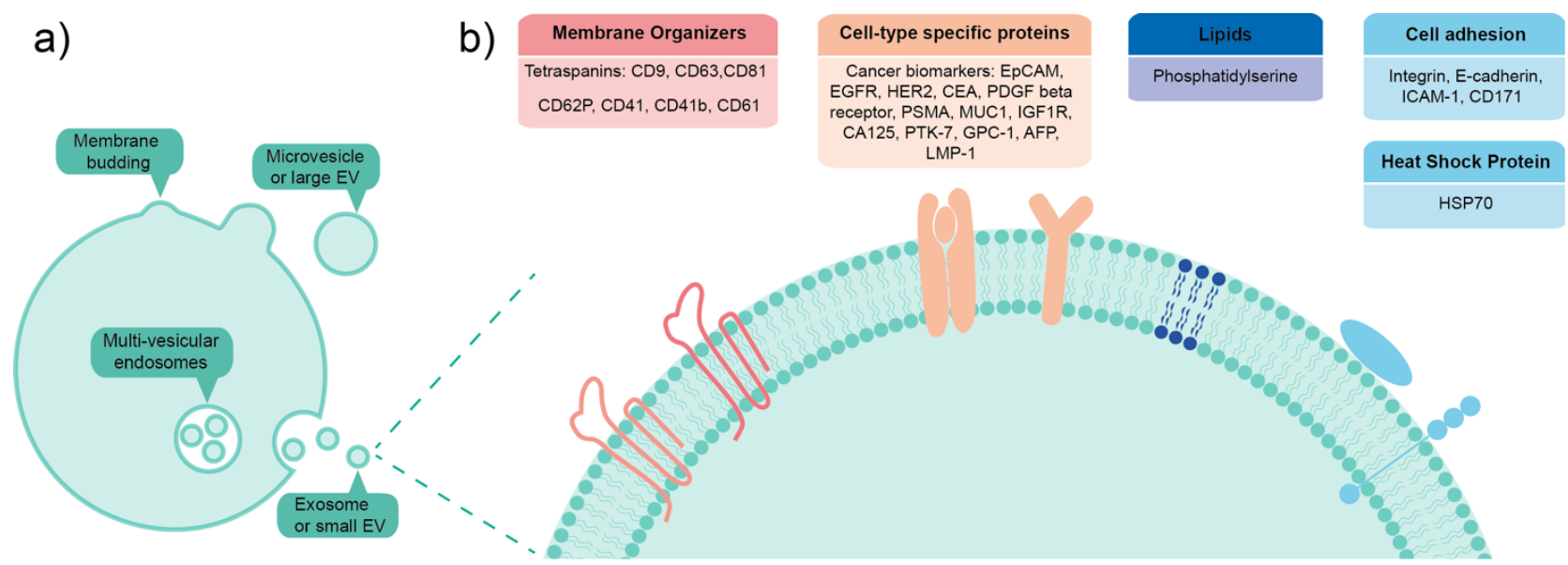

Figure 1: a) EVs are lipid vesicles that originate from parent cells and are often categorized by their excretion mechanism, whether they bud from the cell plasma membrane or whether multi-vesicular endosomes fuse with the plasma membrane to release intraluminal vesicles b) Focus on EV external biochemical composition, listing several of the targeted surface markers described in this review. Figure inspired from ref. 2. 


\section{Antibody affinity-based methods}

\section{Microfluidic devices}

The first paper that described EV isolation based on microfluidics was published in 2010.28 Their microfluidic device could isolate EVs from cell culture supernatant or serum samples without UC processing. The capture process was achieved in a PDMS chip wherein anti-CD63 antibodies were coated on a silanized surface through avidin and biotin linkage. Using CD63 tetraspanin as a target membrane protein, a generic detection and isolation of EVs was achieved. Besides capture, a release approach can be interesting for downstream functional studies of EVs. Hisey et al. ${ }^{40}$ have proposed a microfluidic device for EV capture from serum samples by targeting EVs with anti-CD9 antibodies and anti-EpCAM antibodies. EVs were then released using a low $\mathrm{pH}$ buffer to decrease interaction between probe and ligand and subsequently neutralized. Another release mechanism has been proposed by Qi et al. ${ }^{41}$ They developed a device for EV isolation using porous silicon nanowires coated with anti-CD63 antibodies. EVs were released after 8 hours of nanowire dissolving which is nonetheless still longer than isolation of EVs by UC.

Limit of detection (LOD) is also an important parameter to be determined in the biosensor field. The integration of photonic crystal-based biosensors into a microfluidic device, allowed the distinction of two EV populations (host and parasite) through specificity of CD63 capture ${ }^{42}$ with a LOD of $2.18 \times 10^{9} \mathrm{EVs} / \mathrm{mL}$, as shown in Figure 2.
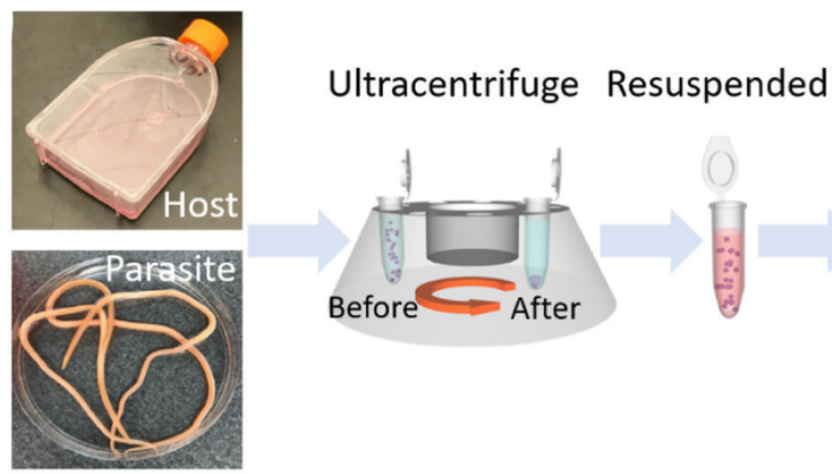

\section{EV detection}
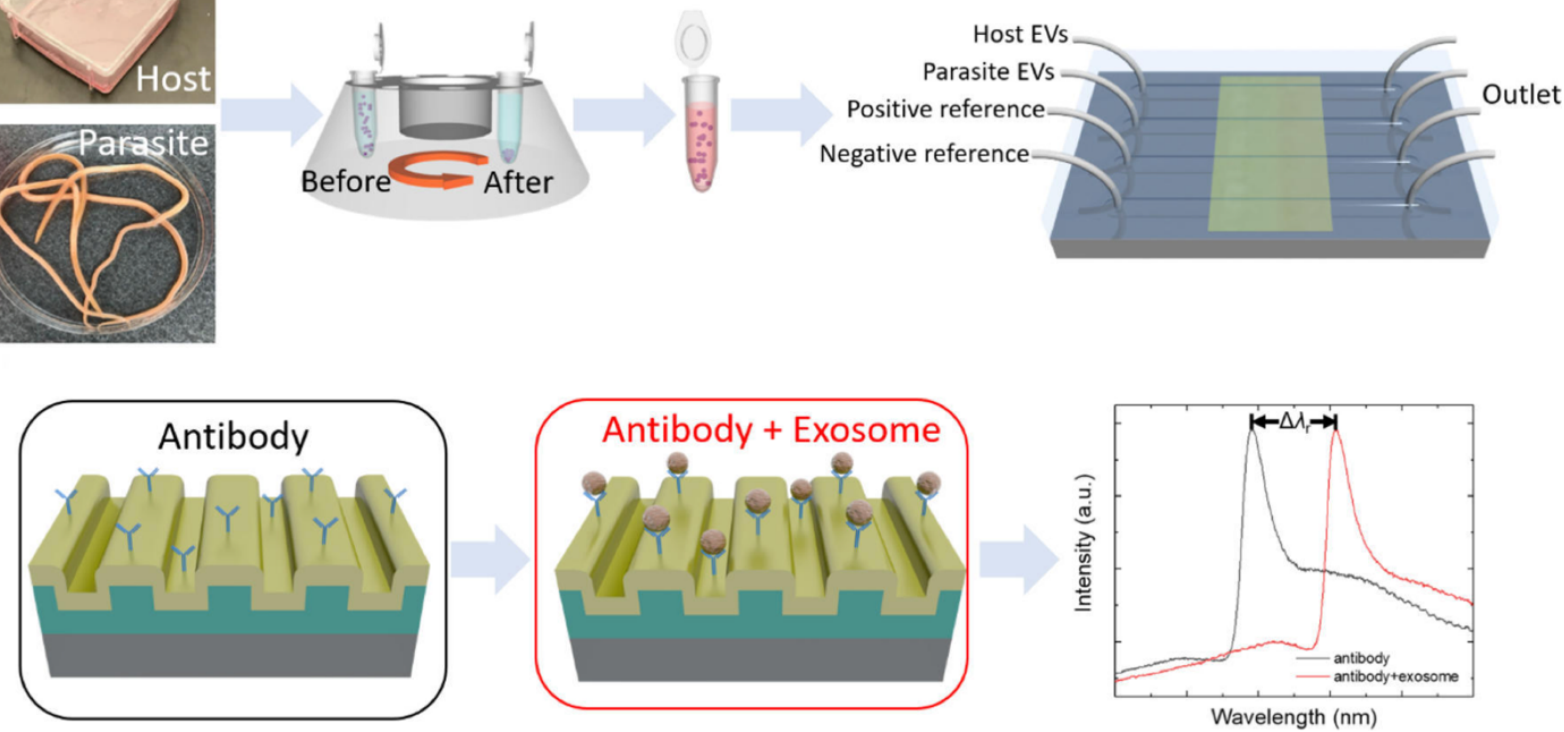

Figure 2: Schematic principle of host and parasite EV differentiation in an anti-CD63 antibody-coated microfluidic chip coupled to a photonic crystal biosensor. EV binding signal corresponds to the spectral shift $\Delta \lambda_{r}$. Reprinted with permission from ref. 42. Copyright 2018 American Chemical Society. 
Reátegui et al. ${ }^{17}$ proposed a microfluidic device functionalized with antibodies directed against cancer biomarkers to capture tumor-derived EVs. They designed a staggered herringbone mixing surface to promote the number of interactions between EVs and antibody-coating through micro-vortices. Their LOD was $1 \times 10^{5} \mathrm{EVs} / \mathrm{mL}$ and they also proposed a recovery of EVs using proteinase $\mathrm{K}$ and a base layer dissolution. Shao et al. ${ }^{43}$ and Dudani et al..$^{44}$ functionalized microfluidic devices with anti-CD63, anti-EpCAM and anti-EGFR. Some of the proteins expressed on EVs were related to their parent-cell origin, therefore targeting those proteins will make specific diagnosis possible and allow the fractionation of different EV subpopulations. The two platforms cited above have a final Polymerase Chain Reaction (PCR) step in the microfluidic chamber to analyze exosomal RNA. Exosomal RNA contains information of proteins in the process of being synthetized, reflecting cell state, which may also enable cancer diagnosis. Three papers $17,45,46$ described a microfluidic device for EV processing from clinical samples. In addition to targeting a large range of biomarkers (CD9 and CD81 tertraspanins; CD62P, CD41, and CD61 specific platelet proteins; EGFR, EpCAM, $\alpha$-IGF1R, an insulin-like growth factor and CA125, a mucin family glycoprotein to target tumor-derived EVs), they performed different downstream analyses. He et al. ${ }^{45}$ identified protein concentrations in EV samples thanks to fluorescence and intravesicular protein analysis and Reátegui et al. ${ }^{17}$ characterized EV RNA from glioblastoma multiforme patients. These technologies are promising to investigate metastasis and potentially to enable early stage diagnosis of cancer from a few microliters of blood.

\section{Plasmonic devices}

Surface Plasmon Resonance (SPR) is an interesting technique in terms of real-time response and quantitative detection of biological objects. Another advantage of SPR sensing is the parallel assessment of different probes on the same surface. As described by Zhu et al., ${ }^{47} \mathrm{EVs}$ were detected with 6 different antibodies (anti-CD9, anti-CD63, antiCD81, anti-CD41b, anti-EpCAM, anti-E-cadherin). Two other similar papers reported SPR sensing to detect EVs with anti-ICAM-1 (Intercellular Adhesion Molecule 1), anti-CD63 and anti-EGFR-vIII. ${ }^{48,49}$ One showed that they could determine the expression level of ICAM- 1 on EVs with less than $400 \mu \mathrm{L}$ of sample. ${ }^{48}$ Qiu et al. ${ }^{49}$ designed a SPR sensor with titanium nitride instead of gold. Anti-CD63 antibody surface grafting allowed the immobilization of $\mathrm{CD}^{+} 3^{+}$EVs showing a LOD improvement of $15 \%$ compared to conventional gold SPR surface. This biosensor was validated with biological samples using mouse serum targeted by anti-EGFRvIII antibody. Zeng et al. ${ }^{50}$ developed a plasmonic interferometer array biochip, i.e. a simplification of the SPR principle. They targeted EGFR cancer biomarkers on EVs derived from lung cancer cell lines reaching a LOD of $3.86 \times 10^{8} \mathrm{EVs} / \mathrm{mL}$. The main advantage of their platform is the miniaturization and portability of their device. 
Some SPR devices are focused on one single biomarker, as developed by the group of J. Dostálek. ${ }^{51}$ To address the problem of diffusion-limited binding kinetics of EVs on the SPR sensor surface, magnetic nanoparticles (NPs) were grafted to EVs. This enabled preconcentration of the sample directly on the sensor surface by using magnetic forces, thus enhancing the signal by increasing the mass transfer rate. ${ }^{51}$ According to NTA measurements, results showed that EVs could be detected at a concentration as low as $7.8 \times 10^{7} \mathrm{EVs} / \mathrm{mL}$ (value calculated using the Avogadro constant from the given concentration of $130 \mathrm{fM}$ ). This concentration was previously inaccessible using classical SPR devices or with sandwiched magnetic NP assays. Similarly, Wang et al..$^{52}$ developed a SPR sensor with dual NP amplification reaching a LOD of $5 \times 10^{3} \mathrm{EVs} / \mathrm{mL}$.

Another type of device has been developed by Liang et al., 53 a nanoplasmon-enhanced scattering (nPES) assay. By functionalizing a microarray with anti-CD81 antibodies, EVs were captured and then detected thanks to anti-CD63 and anti-CD9 antibodies coupled to gold nanospheres and gold nanorods, as shown in Figure 3. This combination produced a local plasmon effect that enhanced the sensitivity and specificity of EV detection. This technique was demonstrated on pancreatic cancer-derived EVs and it outperformed ELISA, requiring only $1 \mu \mathrm{L}$ of biological sample and 5 hours of analysis time, making this device a promising diagnostic tool.
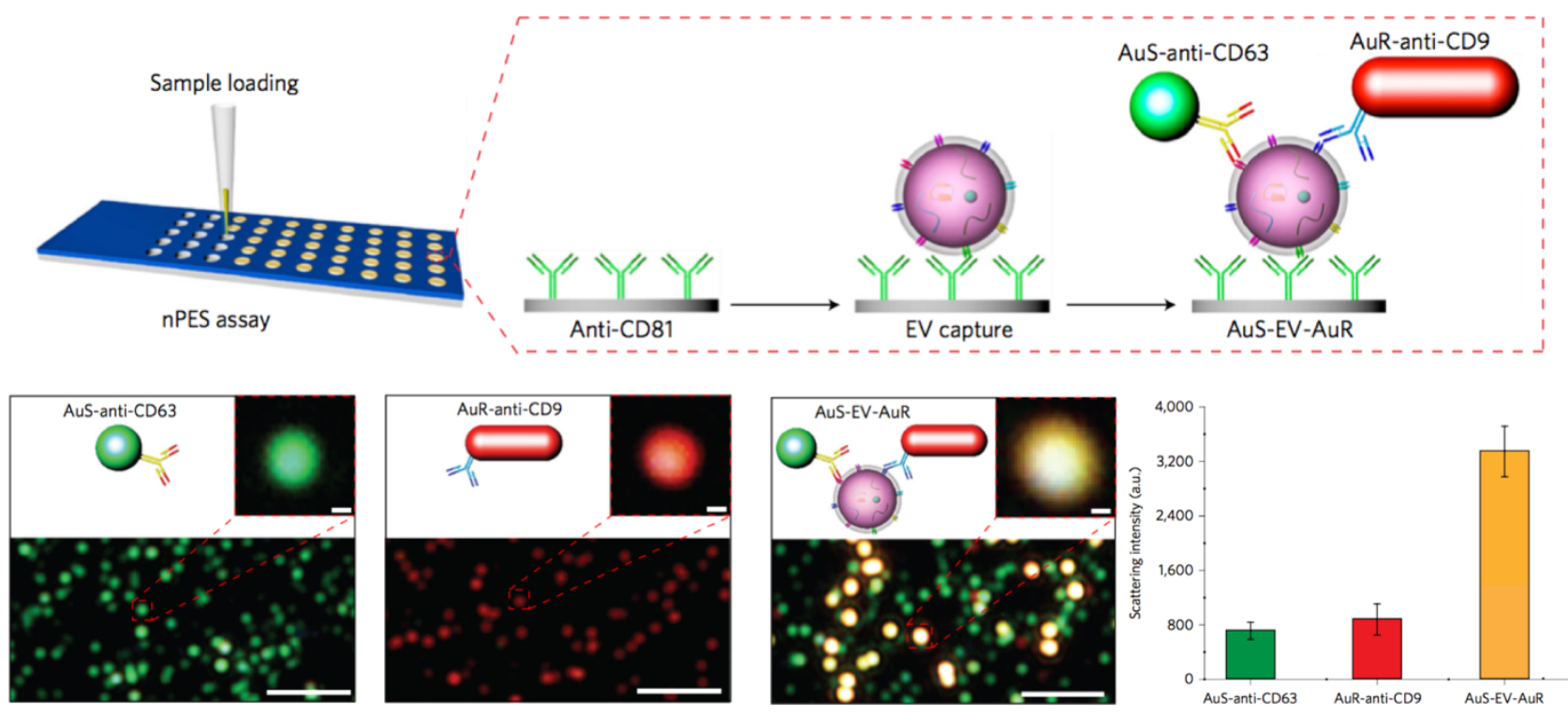

Figure 3: Capture and detection of EVs inside a nanoplasmon-enhaced scattering (nPES) array using antibodies targeted towards the three tetraspanins. Signal is enhanced when both CD63 and CD9 are present on EVs (yellow signal). Scale bars: main images, $2 \mu \mathrm{m}$; magnified images, $100 \mathrm{~nm}$. Reprinted with permission from ref. 53. In the processing of asking for Copyright approval 2017 Springer Nature. 


\section{Other optical devices}

Flow cytometry. Flow cytometry was originally designed to provide multiplexed analysis of cells based on their physical properties and their surface composition. Some EVs are too small to be detected by flow cytometry therefore an adaptation of the technique, based on antibody-coated beads, has been developed. $21,22,54,55$ Koliha et al. ${ }^{56}$ described an original multiplex bead-based flow cytometry platform for the analysis of different subpopulations of EVs. Beads covered with up to 39 capture antibodies were used to form a bead-EVs complex making flow cytometry analysis possible. The combination of capture antibodies and fluorescently labelled detection antibodies allowed EV profiling of both of the targeted surface markers. Depending on EV's origin, natural killer cell or platelet, different tetraspanin compositions were characterized.

Raman spectroscopy. Raman spectroscopy is commonly used to provide a structural fingerprint of analyte molecules. This method has been adapted by Carney et al. ${ }^{57}$ in order to distinguish EV subpopulations. They developed a platform to simultaneously optically trap single EVs and perform Raman spectra measurements. Using FITC-conjugated antiCD9 antibodies they isolated $\mathrm{CD}^{+}$EVs from other EVs present in solution. They quantified biomolecular composition variance among subgroups reporting $\mathrm{CD}^{+} \mathrm{EV}$ subset to have less chemical heterogeneity and reduced component concentration compared to bulk vesicle population. Going further into the capture and analysis of EVs, Beekman et al..$^{58}$ developed a multi-modal analysis platform for SEM, Raman Spectroscopy and AFM measurement on the same chip at the individual EV level. Capture was done in a microfluidic chip using an anti-EpCAM coated surface, then retained EVs were fixed and dehydrated prior to downstream analyses. Combination of these three techniques revealed size distribution and chemical fingerprint of tumorderived EVs with good correlation. A characteristic lipid-protein band was found for Raman measurements and the size range given by AFM was 54 to $3840 \mathrm{~nm}$, revealing an important sample heterogeneity, which is one of the major challenges to be addressed in EV analysis. Another optical biosensor combining immunoaffinity and surface-enhanced Raman scattering was developed by the team of Bang-Ce Ye.59 They first captured EVs with anti-CD9 magnetic beads then, incubated the sample solution with nanoprobes that could bind the lipid membrane of EVs thanks to a cholesterol anchor and finally, collected Raman spectra. The LOD of the biosensor was $2.7 \times 10^{4} \mathrm{EVs} / \mathrm{mL}$ which is among the lowest reported LODs. Moreover, this method was tested on human serum samples and resulting EV concentrations were comparable to the ones obtained via the TRPS technique. Raman Spectroscopy appears like a promising method to precisely analyze EV composition and address heterogeneity by measuring EVs one by one. However, Raman spectroscopy is quite time-consuming to perform at a high-throughput scale.

Interferometric Reflectance Imaging Sensor. Another optical sensing device which looks promising in terms of on-chip isolation and characterization has been developed. ${ }^{60}$ SingleParticle Interferometric Reflectance Imaging Sensor address nano-objects, such as antibodies and EVs, and as these objects layer up in the chip the contrast signal is 
enhanced. Direct counting and sizing as well as multiplexed phenotyping of different populations of small EVs has been shown using antibodies against the tetraspanins and CD171. Further comparative studies of this technique against NTA and immunoproteomic analyses would be interesting to show the potential ability versus conventional nanoparticle analysis methods.

\section{Electrochemical devices}

Electrochemistry is a mature technique in the biosensor field, it was described for the first time in 1962 by Clark and Lyons for glucose detection. ${ }^{61}$ It has been recently applied to the detection of EVs with generic EV capture antibodies CD9 and CD63. ${ }^{62} \mathrm{EVs}$ from serum were sorted by magnetic beads functionalized with anti-CD9 or anti-CD63 antibodies. EVs were then sandwiched between these magnetic beads and quantum dots with specific cancer antibodies (anti-FAM134B, a reticulophagy regulator protein expressed in SW48 colon cancer cell lines and anti-HER2 for breast cancer). The molecular structure was then dissolved by $\mathrm{HNO}_{3}$ so as to perform voltammetric quantification of $\mathrm{Cd}^{2+}$ ions. The combination of generic antibodies and cancer specific antibodies is an interesting method to reveal only cancer EVs. EV concentration was detected as low as $1 \times 10^{5} \mathrm{EVs} / \mathrm{mL}$, which is convenient for diluted blood sample applications. However, the indirect analysis of EVs through $\mathrm{Cd}^{2+}$ ions could be a drawback. In addition, the dissolution of EV complex is irreversible and prevents from making other downstream analyses on the same sample. One of the most sensitive EV detection over all biomolecule affinity-based methods was reported by Kilic et al. ${ }^{63}$ An electrochemical impedance spectroscopy biosensor was functionalized with thiol self-assembled monolayer then, neutravidin and finally biotinylated anti-CD81. This microarray surface allowed the capture of hypoxia-induced EVs from MCF-7 cancer cell lines. Compared to classical ELISA detection of EVs (LOD = $2.84 \times 10^{14} \mathrm{EVs} / \mathrm{mL}$ ), this electrochemical device enabled a LOD of $77 \mathrm{EVs} / \mathrm{mL}$, which make this method a reference for the lowest LOD detected in affinity-based biosensors for EVs. Another electrochemical sensor has been developed by Doldán et al. ${ }^{64}$ They reproduced the classical ELISA architecture with a secondary antibody directed against the sandwiched EVs. This secondary antibody is coupled to horseradish peroxidase enzyme to detect the electrochemical reduction of the substrate. With this biosensor, they reached a LOD of $2 \times 10^{5} \mathrm{EVs} / \mathrm{mL}$.

Compromise needs to be done in terms of sensitivity in order to access different types of information. Cavallaro et al. ${ }^{65}$ developed an electrokinetic biosensor for the detection of EVs with a relatively high LOD $\left(2.8 \times 10^{8} \mathrm{EVs} / \mathrm{mL}\right)$ but with an interesting kinetical aspect. A capillary was functionalized with antibodies using the silane/glutaraldehyde strategy and the changes in streaming current $\left(\Delta \mathrm{I}_{\mathrm{S}}\right)$ were monitored as the sample flowed through, as shown in Figure 4. This technique allowed for real-time profiling of EV surface markers. Measurements revealed that the method was able to detect modifications in expression levels of membrane proteins (CD63 and EGFR). 

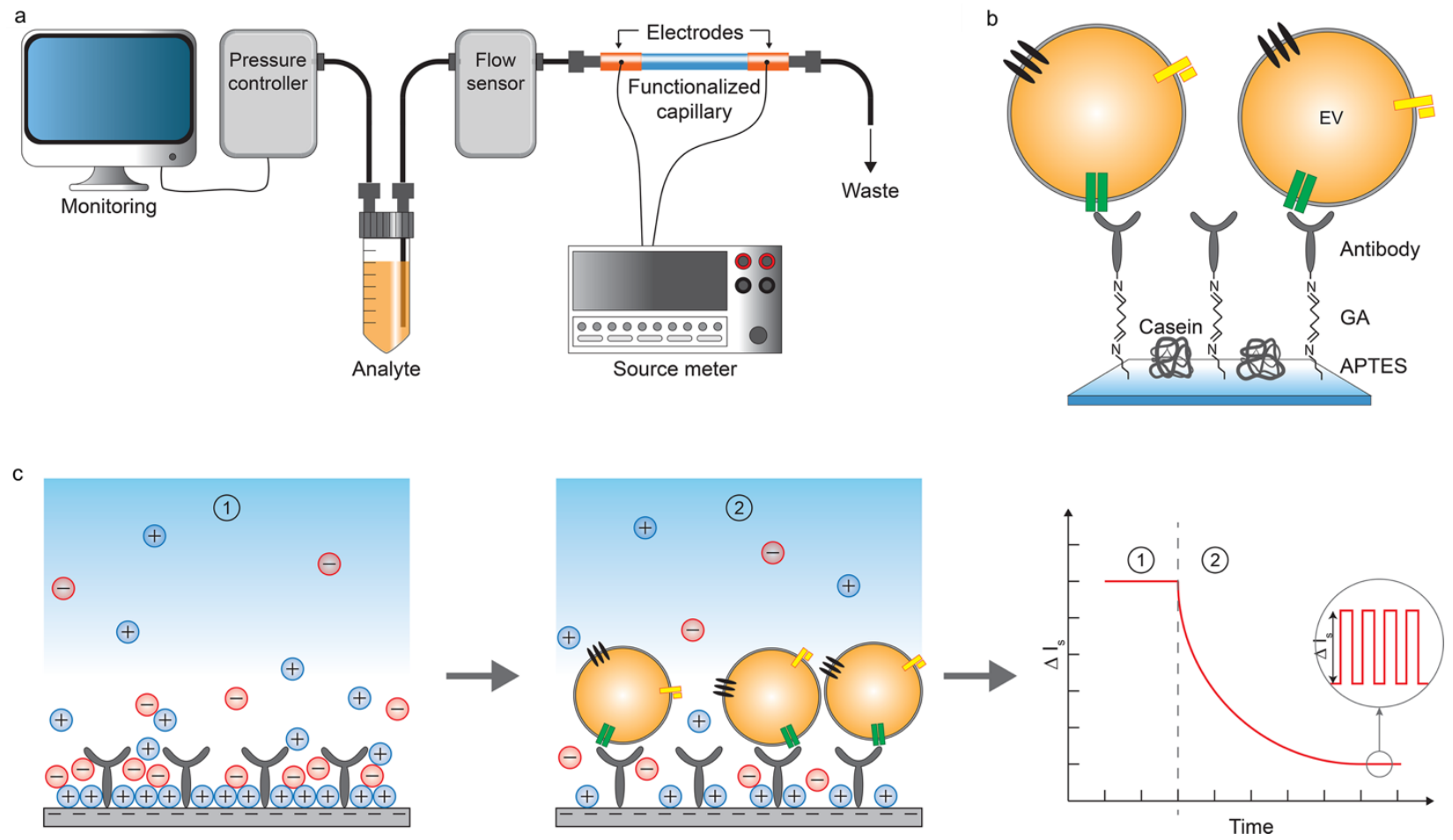

Figure 4: Immunocapture of $E V$ s in a functionalized capillary for electrokinetic biosensing. The change in streaming current ( $\left.\triangle I_{S}\right)$ is proportional to EV binding. Reprinted with permission from ref. 65. Copyright 2019 American Chemical Society.

\section{Conclusion}

In this section dedicated to antibody affinity-based methods for EV isolation and detection, tetraspanins are prominent and the most targeted proteins on EV membranes. This is further confirmed by the paper of Z. Andreu and M. Yáñez-Mó ${ }^{66}$ where they describe the role of proteins from the tetraspanin family from biogenesis to function. In all the biosensors described above, anti-CD63 is the most used antibody and therefore a generic biomarker for EV detection. Compared to non-specific detection methods, antibodies allowed the targeting of EVs and the sorting into subpopulations. Lateral Flow Assays - also known as immunochromatographic assays - are promising tools for lowcost and rapid detection of EVs where revelation is visible to the naked-eye. OliveiraRodríguez et al ${ }^{67}$ developed a lateral flow assay for EV detection using anti-CD9 and antiCD81 as capture antibodies. These simple biosensors are interesting for commercial purpose and point-of-care applications if sensitivity can be improved. It is also relevant to use specific antibodies to detect and isolate EVs linked to certain diseases, for example anti-EpCAM and anti-HER2 for tumor-derived EVs. Handling proteins can be challenging due to stability issues, thus casting doubt on the potential of the long-term commercial development of antibody-based biosensing applications. Despite this, antibodies remain so far the gold standard in terms of diversity to target EVs. 


\section{DNA affinity-based methods}

As an alternative to antibodies, sensors using other biomolecules are emerging. DNA aptamers are single-stranded oligonucleotide sequences whose three-dimensional structure gives the molecule a conformation which allows it to bind to a specific target. These sequences are identified from oligonucleotide banks that may contain up to $10^{15}$ different sequences by an in vitro combinatorial selection method: SELEX (Systematic Evolution of Ligands by EXponentiel enrichment). ${ }^{68,69}$ It is on the basis of target-probe recognition that the aptamers' sequences are characterized. DNA aptamers, mimicking antibody affinity, are currently being developed and are considered to be promising alternatives to antibody ligands. The key advantages of these molecules are: unparalleled ease of production, very high stability in air, similar affinity constants to antibodies, and compatibility with many organic solvents.

By analogy with antibodies, one should address anti-CD63 aptamer when dealing with a DNA aptamer specific to the CD63 transmembrane protein. However, as done in the literature, from this point on we will simplify the writing to CD63 aptamer.

\section{DNA Aptamer}

Electrochemical aptasensors. In 2016, Revzin's group ${ }^{70}$ was the first - to the best of our knowledge - to develop a biosensor based on DNA aptamer for the detection of EVs. This electrochemical aptasensor was composed of micropatterned gold electrode arrays inserted into a microfluidic flow chamber. First, CD63 aptamers were immobilized on the gold surface thanks to thiol moieties. Then, a complementary probe, coupled to a redox group, was hybridized with CD63 aptamer, resulting in an electrochemical signal. EVs were injected in the fluidic chamber where they interacted with the aptamers, triggering the release of the probe and a decrease of the electrochemical signal. In such a configuration, the electrochemical signal change was directly related to the analyte concentration reaching a LOD of $1 \times 10^{6} \mathrm{EVs} / \mathrm{mL}$. Another biosensor based on electrogenerated chemiluminescence was developed by combining 2D nanosheets with CD63 and EpCAM aptamers. ${ }^{71}$ The excellent conductivity and catalytic properties of 2D materials is indeed an asset for an electrochemical device enabling here a relatively low LOD $\left(1.25 \times 10^{5} \mathrm{EVs} / \mathrm{mL}\right)$, but the assembly process seems quite complex to set up.

Colorimetric aptasensors. Xia et al..$^{72}$ functionalized single-walled carbon nanotubes with CD63 aptamer to design a biosensor for EV detection where detection is visible to the naked-eye. The CD63 aptamer was absorbed onto the carbon nanotubes' surface via noncovalent interactions. In the presence of EVs, the aptamer could then bind to CD63 and undergo a structural change. Carbon nanotubes then returned to their initial state and the catalytic degradation of $\mathrm{H}_{2} \mathrm{O}_{2}$ decreased, inducing a color change of the solution that could be observed either by naked eye observation or UV-vis spectrometer as shown in Figure 5. By developing this type of biosensor, they constructed the first label-free aptasensor for EV detection. Using aptamers instead of antibodies improved the stability 
and the sensitivity of the system and decreased production costs. The amplification process enabled by horseradish peroxidase enzyme achieved a LOD of $5 \times 10^{8} \mathrm{EVs} / \mathrm{mL}$. The signal-off (blue color when there are no EVs) and the signal-on(transparent solution) strategy visible to the naked-eye is promising for point-of-care applications. However, NPs are potentially a biohazard and not yet fully approved for handling outside a laboratory environment.

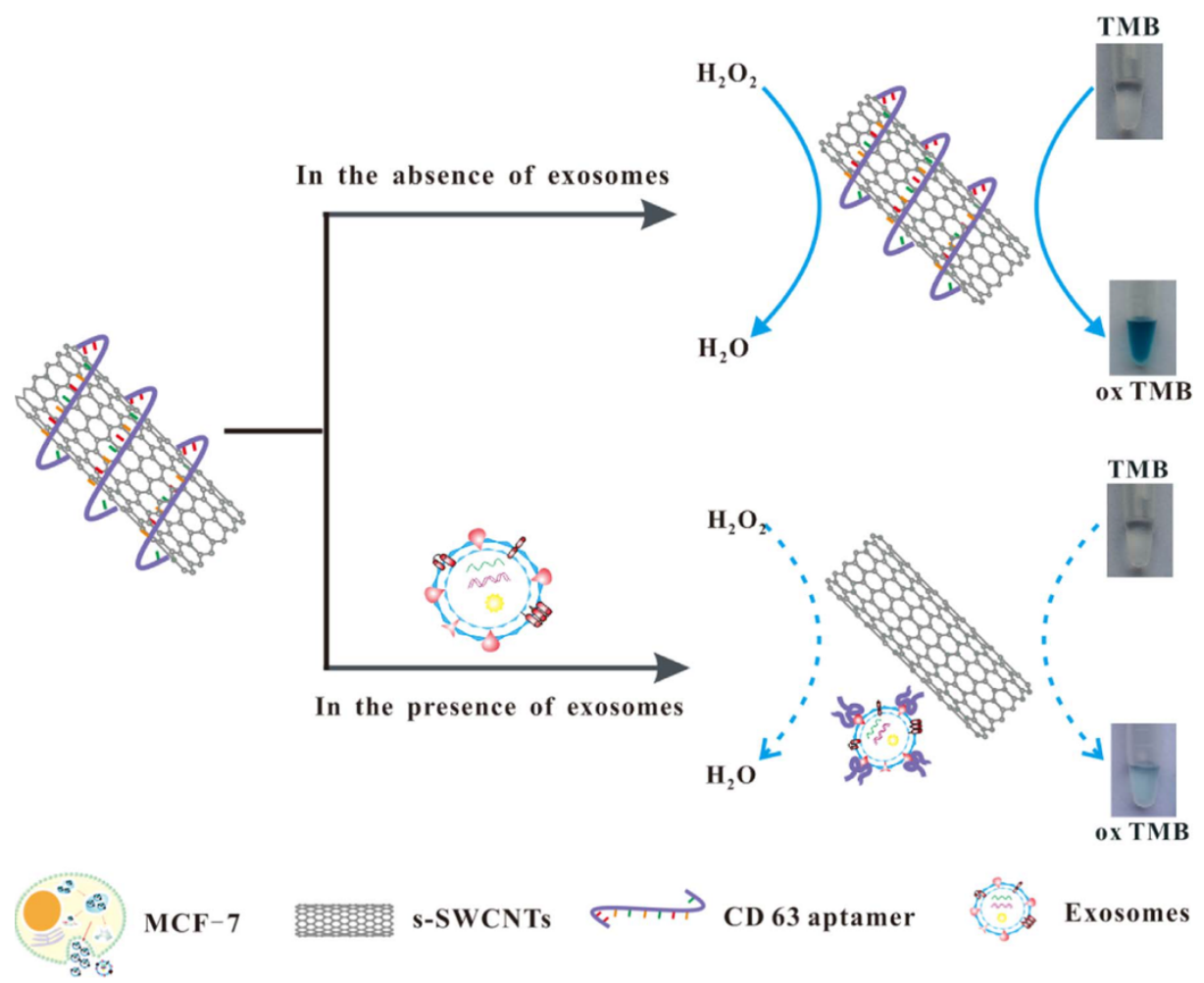

Figure 5: Aptamer functionalized carbon nanotubes for biosensing of EVs. The color change of the solution can be observed by the naked-eye. Reprint from ref. 72, in the processing of asking for Copyright approval 2017 Elsevier.

Fluorescence-based aptasensors. Zhang et al..$^{73}$ described a method based on polarized excitation light using dye-labeled CD63 aptamer. The fluorescence variation of the dyelabeled aptamer is proportional to EV concentration in the sample. EV concentrations calculated by this method agree with concentrations obtained with NTA measurements, which are regarded as the gold standard. Moreover, this method was validated on human plasma and it is quite easy to perform as it only needs $1 \mu \mathrm{L}$ of sample and only $30 \mathrm{~min}$ to determine the concentration. However, the aptamer specificity was not assessed, for instance, by using another DNA oligonucleotide sequence. This method is promising but should be verified with an unspecific DNA oligonucleotide to check the aptamer specificity. Another very recent paper $^{74}$ demonstrated a very sensitive detection of EVs with the CD63 aptamer using photonic crystals. They reported the use of a very low amount of sample $(20 \mu \mathrm{L})$ and a LOD of $8.9 \times 10^{3} \mathrm{EVs} / \mathrm{mL}$. 
Given the lack of low cost methods to detect and quantify EVs, a paper-based aptasensor was designed..$^{75}$ A CD63 aptamer was split into 2 different strands which formed a binding pocket in the presence of the specific target. The first CD63 aptamer fragment was grafted onto the functionalized paper thanks to the aldehyde groups of cellulose. When EVs were added to the paper sensor along with the second CD63 aptamer fragment (hybridized with gold NPs), the distance between the paper and the gold NPs was reduced, resulting in luminescence quenching. This technology is sensitive (LOD of $1.1 \times 10^{6} \mathrm{EVs} / \mathrm{mL}$ ) for EV detection, portable and low-cost. However, this self-quenched luminescence might be complicated to observe in the presence of a complex biological sample such as blood.

Using the generic CD63 aptamer, fluorescence resonance energy transfer method based on $2 \mathrm{D}$ nanosheets was developed. ${ }^{76}$ EVs were detected using 1000 times lower amount compared to the conventional ELISA method. To address diagnosis purpose, PSMA (prostate specific membrane antigen) and PTK-7 (tyrosine-protein kinase-like 7) aptamers were added to the biosensor and different cell lines were also investigated. Chemical development of a near-infrared polyelectrolyte has been made by Lyu et al. ${ }^{77}$ Using quencher-tagged aptamers targeted towards four EV proteins (CD63, EpCAM, HER2, MUC1, a carcinoma biomarker over-expressed on MCF-7 EVs) they were able to distinguish between benign and cancer-cell-secreted EVs. Such a platform enables an orthogonal analysis of multiple EV samples. Moreover, this device is the first optical biosensor to work without real-time light excitation for $\mathrm{EV}$ detection.

Differentiation of EV's origin (from cancerous or non-cancerous cells), was achieved by Zhang et al. ${ }^{78}$ They designed a self-quenched fluorescence aptasensor based on MUC1. In the presence of tumoral EVs, the dye-labeled aptamer emits fluorescence whereas it is quenched in the absence of EVs. However, there is a major drawback related to nonspecific responses due to free proteins in serum having a similar size to EVs. Indeed, nonspecific interactions of biomolecules with biosensors is a critical issue when working with samples as complex as blood. Two very similar papers have been published in 2018 showing promising clinical applications. ${ }^{79,80}$ On one side, Wang et al., ${ }^{79}$ demonstrated enzyme-aided fluorescence amplification based on graphene-oxide-DNA aptamer interactions for EV detection. The platform consisted of labeled CD63 and EpCAM aptamers adsorbed onto graphene oxide. In the presence of EVs, aptamers were released from the graphene oxide and would bind to EVs releasing a fluorescence signal. They validated their technology with cancerous EVs from clinical serum sample. The advantage of this biosensor is its simplicity of use and time-efficiency (only $30 \mathrm{~min}$ to isolate EVs from serum sample). However, even using DNase I enzyme amplification, the LOD is $2 \times 10^{7} \mathrm{EVs} / \mathrm{mL}$, while Jin et al., ${ }^{80}$ with the same amplification enzyme, accessed 100-fold lower LOD (1.6×105 EVs/mL). Playing with seven different aptamers (targeting the following proteins: CD63, EpCAM, PTK-7, PSMA, PDGF, CEA: CarcinoEmbryonic Antigen, and AFP: a-fetoprotein) and five different cell lines, this simple platform showed protein proofing of cancerous EVs. Additionally, this device was validated on blood samples of prostate cancer patients, making it a powerful diagnostic device. 
Nanoparticles functionalized with aptamers. Yu et al. ${ }^{81}$ used magnetic NPs functionalized with CD63 aptamers and hybridized with labelled complementary sequences. In the presence of EVs, the complementary sequences were released and a fluorescence signal proportional to EV concentration was recorded. Another interesting property of the CD63 aptamer, revealed after the authors investigated three different complementary sequences, is that the binding site of CD63 on the aptamer may be near to the $5^{\prime}$ end. Although relatively simple to implement, this methods suffers from low sensitivity with a LOD of $1 \times 10^{9} \mathrm{EVs} / \mathrm{mL}$. Alternative NP detection methods have been developed to amplify the signal and improve the LOD. After developing a 2-step method with oligonucleotide and anti-CD9 antibody for direct EV quantification, ${ }^{82}$ Bang-Ce Ye's team proposed a quite similar detection method that also included isolation. ${ }^{83}$ Combining magnetic beads with cholesterol anchors, EVs were trapped and sandwiched in between these magnetic beads and CD63 aptamer-decorated copper NPs. This complex was formed depending on targeted EV concentration in the sample. Then, NPs were dissolved in $\mathrm{HNO}_{3}$ and copper formed a complex with ascorbate. The resulting fluorescence signal was an indirect titration of EV concentration. The total processing time was 2 hours with a LOD of $4.8 \times 10^{7}$ particles/mL. ${ }^{83}$ Similarly, an amplification process with electrochemistry was performed with a ruthenium complex to monitor EV concentration. One advantage of this technique is the dual amplification of the signal thanks to the release of multiple DNA strands and the exonuclease recycling process. This amplification strategy permitted a lower LOD as low as $7 \times 10^{4} \mathrm{EVs} / \mathrm{mL}^{84}$ which is - to our knowledge - the lowest LOD reported so far using NPs and aptamers.

Because EVs express different biomarkers on their surface, some which are specific to subpopulations of EVs, Jiang et al. ${ }^{85}$ reported a multiplexed sensor platform for profiling exosomal surface proteins. They functionalized gold NPs using a panel of EV-binding aptamers. Several links occurred between EV surface proteins and their corresponding aptamers resulting in aggregation of the NPs. Thus, a color change from red to blue is the signature of this aggregation. At the same time, the secondary signal, i.e. the absorbance ratio $\left(\mathrm{A}_{650} / \mathrm{A}_{520}\right)$ is related to the number of target proteins present on the EVs surface. This biosensor has been validated on EVs derived from different cell lines. The advantage of such a method is the acquisition of an exosomal protein profile that is a function of cancer type and related to parent cells. This technology could add to the knowledge base of EV surface protein specificity according to the cancer type, its development stage and therapy strategies.

Combining both isolation and detection within the same protocol is quite a technical challenge. Three papers using NPs reported very promising ways to isolate and detect EVs. Wang et al. ${ }^{86}$ combined magnetic beads, gold NPs functionalized by CD63 aptamers, and a Raman reporter molecule. They functionalized gold NPs with aptamers targeting three different proteins (PSMA, CEA, and HER2). A complex was formed between gold NPs, EVs and magnetic beads. The complex was then isolated using a magnet and then detected using Surface-Enhanced Raman Spectroscopy. In a single-step, single-solution 
process, they screened different EV species and achieved promising results for applications in cancer diagnosis.

Anion-exchange isolation method is a well-known method in chemistry. Chen et al. ${ }^{87}$ applied this method to isolate EVs. Anion-exchange magnetic beads decorated with EpCAM aptamer were incubated in plasma and cell-culture media. The negatively charged phosphatidylserine present on EV membranes allows to form a complex with the anion-exchange magnetic beads. They reached a LOD of $3.58 \times 10^{6} \mathrm{EVs} / \mathrm{mL}$. Zhang et al. ${ }^{8}$ developed a very promising strategy based on magnetic beads coupled to aptamers for EV isolation and release. Generic CD63 aptamers were grafted onto magnetic beads allowing the capture of EVs. To release EVs in a non-destructive manner, a complementary sequence of DNA aptamer was added, as shown in Figure 6. In addition, they assayed biomarker expression levels in different plasma samples using different targeting aptamers, allowing a preliminary diagnostic step immediately after isolation. Compared to CD63 expression, MUC1 expression was significantly higher in the case of cancer patients.

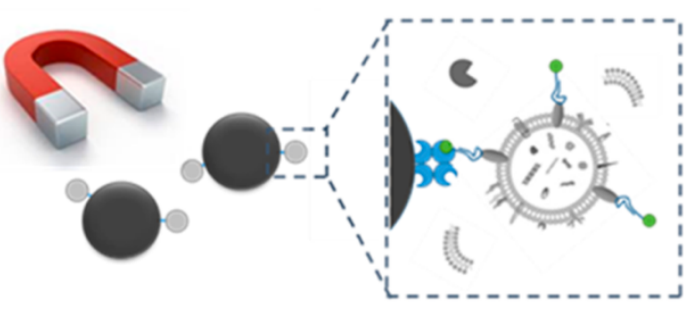

Magnetic Isolation

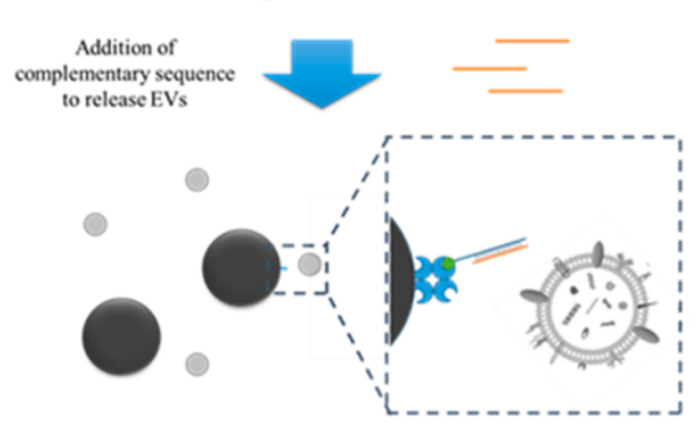

Non-destructive Release

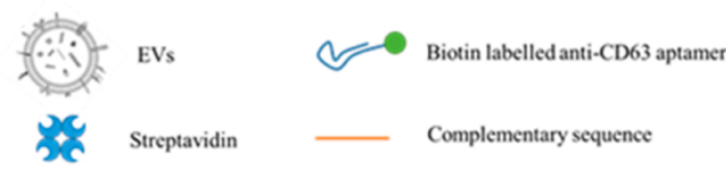

Figure 6: Capture and release of EVs using magnetic beads coupled to CD63 aptamers. Thanks to a complementary sequence, EVs can be release in a non-destructive manner. Reprinted with permission from ref. 88. Copyright 2019 American Chemical Society. 


\section{Combining DNA hybridization probes with aptamers}

Two interesting papers described the combination of DNA oligonucleotide strands with aptamers for EV detection and isolation. Gao et al. ${ }^{89}$ take the advantage of DNA amplification to enable their method. The capture of UC-isolated EVs is carried out with CD63 aptamers hybridized with a DNA probe and grafted onto magnetic beads. After binding EVs with CD63 aptamer, they chose to amplify the released complementary DNA aptamer sequence using a catalytic hairpin DNA cascade reaction. This process lead to the formation of a gold NP-dendrimer complex with a second fluorescence signal amplification. This dual amplification strategy is an original method which achieved a LOD as low as $1.16 \times 10^{6} \mathrm{EVs} / \mathrm{mL}$. It also provides a platform for EV quantification with a DNA-mediated signal amplification. However, this technique depends on EV isolation by UC. On the other hand, a microfluidic device was described by Liu et al. ${ }^{90}$ which could both isolate and detect EV subpopulation from a cell-originating EVs mixture. This technique used $\lambda$-DNA as a viscoelastic mediator to allow deviation and sorting of EVs by size (from to $20 \mathrm{~nm}$ to $1 \mu \mathrm{m}$ ). HER2 and EpCAM aptamers were pre-incubated with EVs in order to label them specifically before the sorting step. Labeled EVs were injected into the microfluidic system in association with $\lambda$-DNA. Long viscoelastic $\lambda$-DNA molecules have a linear trajectory along the fluidic chamber while smaller vesicles are directed towards the edges of the chamber, as shown in Figure 7. After the sorting device, different populations of EVs and related biomarkers (targeted by aptamers) are distinguished via fluorescence. Using biomarker expression, differentiation between small and large EVs may be used as a method of cancer diagnosis. As demonstrated by these two articles, combining DNA oligonucleotides with aptamers for detection and isolation of EVs is a promising way to separate EV sub-populations. 
a

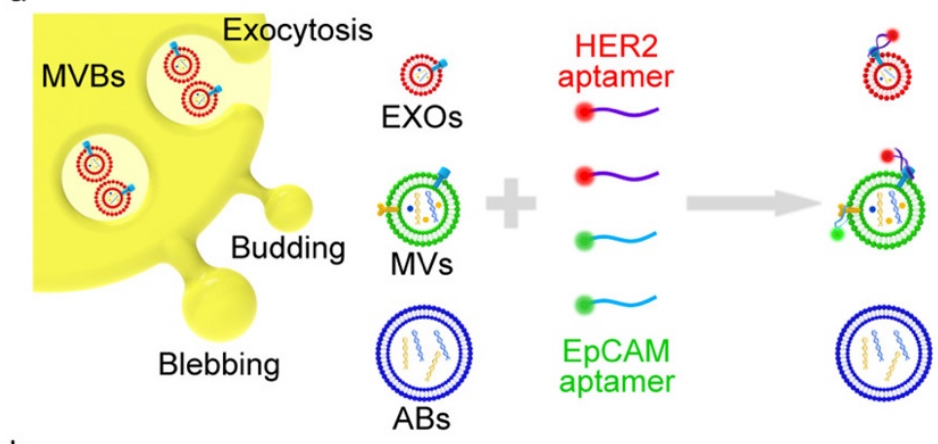

b

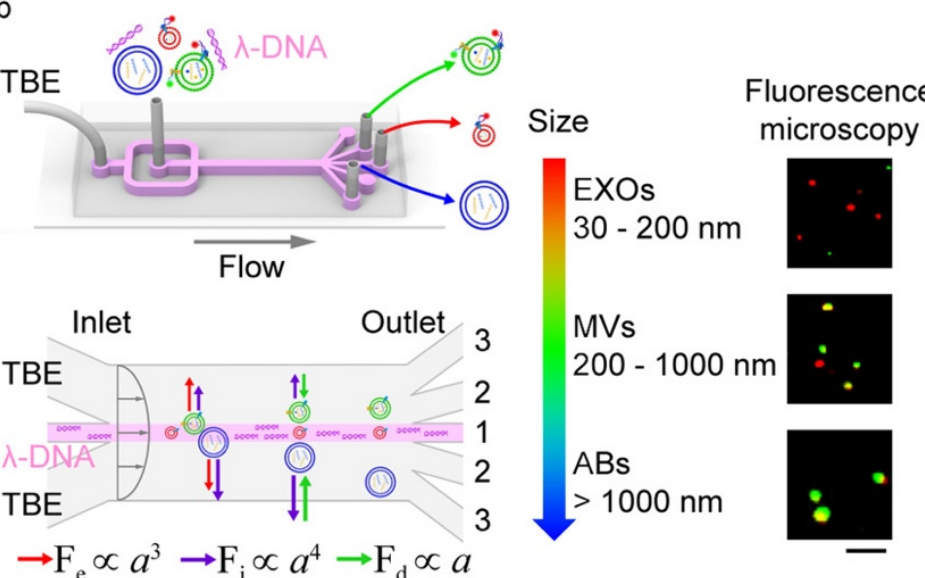

Figure 7: Aptamer-based analysis and $\lambda$-DNA microfluidic sorting of different EV populations, such as exosomes (EXOs, red), microvesicles (MVs, green), and apoptotic bodies $(A B s, b l u e)$ in TBE buffer. $F_{e}, F_{i}$ and $F_{d}$ are different forces exerted on the vesicles inside the microfluidic device, all those forces are proportional to a which is the size of the vesicle. Scale bar is $5 \mu \mathrm{m}$. Reprinted with permission from ref. 90. Copyright 2019 American Chemical Society.

Schematic of $\lambda$-DNA-mediated sorting of EV subpopula- tions and aptamer based analysis of individual EVs. (a) Labeling of cell-originating EVs including exosomes (EXOs, red), microvesicles (MVs, green), and apoptotic bodies (ABs, blue) with fluorescent HER2 and EpCAM aptamers. (b) Size-selective separation of EV subpopulations by $\lambda$-DNA mediated viscoelastic microfluidics. Fluorescence microscopy images showed HER2 (red) and EpCAM (green) expression of isolated individual EVs. Scale bar, $5 \mu \mathrm{m}$.

\section{Dual method Antibody-DNA}

In some devices, a dual method including two different biomolecule types - antibodies or peptides with DNA oligonucleotides - were used to amplify the biosensor signal. Tian et al..$^{91}$ developed a digital detection method using an anchor molecule linked to a DNA oligonucleotide. EVs were detected using a rapid isothermal nucleic acid assay similar to digital PCR. Their technique was validated on cancer cell line-derived EVs using a DNAconjugated anti-glypican-1 (GPC-1) antibody. This strategy is particularly interesting to analyze EV samples, first on a large scale and then to detect specific cancer EVs. He et al. 92 developed a method that can directly visualize and quantify EVs at the single vesicle level. EVs were sandwiched between anti-CD63 antibodies and aptamers targeted 
towards PTK-7. This technique could distinguish between tumor and control subjects using only $1 \mu \mathrm{L}$ of plasma. A detection system using proximity ligation assay was proposed by Liu et al. ${ }^{93}$ to detect two other cancer biomarkers, EGFR and LMP1 (EpsteinBarr virus latent membrane protein 1). They imagined a system targeting these biomarkers using two antibodies respectively conjugated to DNA oligonucleotides. In the presence of the corresponding biomarker, the antibodies recognized EVs and the two neighboring DNA strands hybridized. A DNA amplification signal was performed by recombinase polymerase amplification, coupled with transcription-mediated amplification. This amplification system produced RNA fragments which were directly in proportion to biomarker concentration. The proximity required for ligation of DNA sequences, along with the amplification, enhanced the specificity of this method. In addition, the colorimetric detection of EV biomarkers was done in a short time (2.5 hours) thus opening promising avenues for the development of this strategy in point-of-care applications. This method has been applied to clinical samples showing that early-stage cancer patients can be diagnosed from plasma samples. The successive binding of EVs by antibody and DNA oligonucleotide is a strategy also employed by Huang et al. ${ }^{94}$ EVs were captured through two successive biomolecules: first by anti-CD63 antibody magnetic beads and then by nucleolin recognition aptamer (AS1411) combined with a rolling circle amplification oligonucleotide primer. After DNA primer elongation, gold NPs coupled to complementary DNA sequences (labeled with fluorescein dye) hybridized with the aptamer containing the DNA primer extension. Labeled DNA molecules were released from gold NPs by exonuclease activity, significantly increasing the fluorescence signal. The advantage of this technique is the high sensitivity and specificity of EV's response. These dual-signal amplification strategies allowed to achieve LODs as low as $1 \times 10^{2} \mathrm{EVs} / \mathrm{mL}^{93}$ and $1 \times 10^{5} \mathrm{EVs} / \mathrm{mL} .{ }^{94}$

\section{Conclusion}

Many sequences of DNA aptamers have been described in the literature but only a few have been reported for EV capture by targeting the following proteins: CD63, EpCAM, PDGF- $\beta$ receptor and nucleolin. To summarize, there is one generic EV aptamer and three cancer-specific EV aptamers. Since tetraspanins are common surface markers for EVs, it would be interesting to isolate CD81 and CD9 aptamers by the SELEX method. To address this challenge, Hong et al. ${ }^{95}$ developed a multifunctional screening platform for aptamer selection in a microfluidic manner. The method has the advantage of both to decreasing the rate of non-specific folding, and also permitting simultaneous negative and positive selection of biological target analytes. Wang et al. ${ }^{96}$ developed an aptasensor with expanded nucleotides ${ }^{97}$ for the detection of EVs. Moreover, they used DNA origami to nanostructure and orient the immobilization of aptamers which improved the accessibility of the sensors surface. Finally, new types of profiling tools based on DNA are currently being developed as adaptive dynamic artificial poly-ligand targeting which is a next generation approach in systems biology. ${ }^{98}$ This paper shows the importance of the development of aptamer-based methods to detect different EV subpopulations. Targeting 
these complex biological vesicles with aptamers, that are more chemically stable and easier to handle, is thus highly promising for point-of-care applications.

\section{Peptide affinity-based methods}

As discussed previously, immunoassays are interesting due to the very large range of biomolecules that can be targeted. However, working with proteins is labor intensive since they are complex to modify and the obligation to manipulate them in aqueous buffers can be limiting for certain types of applications. Similarly to DNA aptamers, short protein fragments or peptides, are an emerging class of biomolecules. Engineering of peptides is an alternative way to target biological objects with easily tunable functional groups.

\section{Emerging peptide probes dedicated to EVs}

Today, biomolecule chemical synthesis - such as peptide synthesis - is becoming more and more rapid, efficient and low-cost. ${ }^{99}$ Peptides are interesting synthetic ligands for the development of new specific probes for EV isolation and detection. However, so far very few papers have been published so far on biosensors with EV-binding peptides. The challenge of designing efficient peptides for EVs is discussed by Tamura and Yin in their book chapter. ${ }^{100}$ EVs display universal protein markers: tetraspanins, Ras superfamily GTPase proteins and Heat Shock Proteins (HSP). In addition, lipids that compose the membranes of EVs are also interesting targets for peptide probe design. Based on the fact that EV lipids are enriched with phosphatidylserine, ${ }^{101}$ Yin's research group, developed three peptides based on characteristic membrane proteins displayed on EVs. ${ }^{100}$ A first peptide probe, based on the intracellular membrane protein Myristoylated Alanine-Rich C-Kinase Substrate (MARCKS), has been developed by Yin's research group. ${ }^{102}$ This synthetic peptide called MARCKS-ED selectively binds phosphatidylserine on EV lipid membranes. Thanks to the numerous phenylalanine residues present in the peptide, the insertion is deeper into the membrane when phosphatidylserine is present at high concentrations. A second peptide probe is described by the same group. ${ }^{103}$ This cyclic peptide called C2BL3C derived from Synaptotagmin-I, a component of the soluble Nethylmaleimide-sensitive factor attachment protein receptor complex. They demonstrated that C2BL3C peptide specifically binds to nanosized lipid vesicles such as EVs. The third peptide probe developed by the same team ${ }^{104}$ is the bradykinin trimer peptide with an increased binding affinity to phosphatidylserine-enriched lipid membranes compared to MARCKS-ED and C2BL3C probes. They labelled the peptide probes with a fluorophore and were able to detect the strong binding of C2BL3C with EVs. The binding is specific to high-curvature lipid membranes, up to $100 \mathrm{~nm}$ diameter vesicle, making this probe very specific to small EVs. For these three described peptides, 
EV working concentrations of about $10^{8} \mathrm{EVs} / \mathrm{mL}$ were determined by NTA. Nevertheless, no LOD was determined for any of these three peptides. Finally, none of these peptides were integrated into a biosensing device, even though their specificity for EVs is undeniable.

\section{Methods of EV isolation and detection using peptide probes}

In the past three years, new peptide sequences have been designed and applied to EV detection and isolation. Different EV membrane proteins were targeted with three new peptide probes: HSP proteins with Venceremin (Vn) peptides, EpCAM with Ep114 peptide and integrins using LXY30 peptides. Lipids constituting EV membranes were also targeted using the cell-penetrating PenArg peptide. Sensing methods have been developed using these new peptide probes, either for isolation or detection. As discussed in the introduction, the most often employed isolation method is UC. However, taking into account the disadvantages of this process, peptide affinity-based methods appear more interesting in terms of purity rate. Ouelette and his team developed the Vn class of peptides that specifically recognizes EVs containing HSP protein. ${ }^{105}$ This was the first proof of principle of EV isolation using the Vn96 synthetic peptide. Cell culture media containing EVs was incubated in the presence of Vn96 peptide for $15 \mathrm{~min}$, the sample was centrifuged, and then EVs-Vn96 peptide complexes were precipitated, without the requirement of any UC process. By targeting HSPs, Vn96 permits the aggregation of EVs facilitating the formation of an EV pellet. Comparison between Vn96-isolated EVs and ultracentrifuged EVs was carried out using NTA, TEM, AFM, and biochemical analysis. The peptide isolation method gave similar results to the conventional UC, confirming the ability of Vn96 to act as an efficient ligand. This method appears to be easily reproducible in bio-chemistry laboratories as it requires only a centrifuge. We note that another team used a similar strategy employing Vn96 peptides and analyzed proteins constituents of EVs using mass spectrometry. They demonstrated that for peptide-assisted EV isolation, 30 times less sample volume was required to assess the same spectrometry results ${ }^{106}$. One year later, the group of Jimenez demonstrated once again the potential of Vn96 peptides for EV isolation. ${ }^{107}$ Proteomic analysis of urinary EVs isolated by Vn96 peptide-based capture was comparable to EVs isolated by UC, confirming that Vn96 peptide isolation is suitable for clinical samples as well as for high-throughput analysis. Vn96 peptide isolation is now employed to perform proteome profiling of EVs, ${ }^{108}$ making it a promising routine isolation method for large-scale diagnosis.

Considering now the peptide affinity-based detection methods, Bally's team developed a nanofluidic device for single EV analysis. ${ }^{109}$ This device consists of hundreds of nanochannels buried into a silicon wafer. A dye-labelled cell-penetrating peptide (PenArg peptide ${ }^{110}$ ) targeting EV membranes enabled the quantification of EVs by fluorescence. As for previously described peptide-targeted lipids, ${ }^{102-104}$ specificity becomes higher with highly curved vesicles, i.e. less than $100 \mathrm{~nm}$ in diameter. This interesting characteristic allowed the quantification of vesicles with a sensitivity of $10^{9}$ 
$\mathrm{EVs} / \mathrm{mL}$ (value calculated using the Avogadro constant from the given femtomolar concentrations) similar to standard NTA analysis. Another device proposed the detection of EpCAM+ subpopulation of EVs. The peptide Ep114 is a peptide ligand which targets the EpCAM protein, that is particularly interesting for cancer diagnosis. Yoshida et al. ${ }^{111}$ developed a strategy of polymer beads coupled to Ep114 to capture EpCAM ${ }^{+}$EVs. A copolymer, mimicking the membrane, is synthetized and Ep114-FITC is grafted via click chemistry. This complex molecule is coated onto either silica beads for fluorescence application or onto polystyrene beads for AFM measurements. Combination of fluorescence and AFM signals of EpCAM+ EVs confirmed the strong binding affinity of Ep114 peptides with EpCAM expressing vesicles. These two techniques, microfluidic and optical, allowed the detection of different subpopulations of EVs captured with specific peptides. Nonetheless, more precise analysis could be performed using Raman spectroscopy. Lee et al. ${ }^{112}$ developed a surface-enhanced Raman Spectroscopy method for the analysis of EVs derived from cancer cells. NPs functionalized with integrin-specific peptide ligand (LXY30), which mediates cellular adhesion, preferentially bound cancer cell EVs, since this integrin is overexpressed in cancer cells lines. Raman peaks corresponding to captured EVs have specific signals characteristic of cancer disease states. However, for non-cancerous EVs, no Raman signal was observed. The specificity of LXY30 peptide avoided sandwich-type immuncomplex for Raman-based detection of EVs. Moreover, by targeting integrins, this method showed promising results for potential early stage cancer diagnosis.

\section{Conclusion}

As already discussed by Tamura and Yin, ${ }^{100}$ the need to find new peptide probes for EVs - targeting for instance protein domains regulating membrane curvature - might help biosensor scientists to develop new peptide forms for the isolation and detection of EVs. The development of an EV target library might be a useful knowledge base to enhance the research of new specific probes either for isolation or detection. However, very few papers in this section mention a LOD or used a clinical sample to validate their methods. This fact shows that only proof of concepts were reported. Testing these promising peptide probes with complex samples such as plasma is the new priority to determine LODs.

\section{Conclusion and Perspectives}

By gathering state-of-the-art publications focused on EV membrane-bound molecular motifs, this Minireview has summarized the recent findings in the field. As demonstrated throughout this review, a variety of EV-targeting ligands are used: antibodies, DNA aptamers, and peptides. However, the difficulty of establishing new probes to target EVs with high specificity appears to be a major challenge. Concerning DNA aptamers, SELEX 
may give access to DNA aptamers specific to any targeted protein, although this technique remains labor intensive and requires rigorous controls ${ }^{113}$. Facing these drawbacks, alternative methods are emerging. Cell-SELEX has been developed to directly target desired transmembrane proteins in living cells. ${ }^{114}$ The main advantage of this technique is the selection of DNA aptamers specific to membrane proteins in their native conformation. The number of cycles required still necessitates several days. Dealing with this challenge, non-SELEX aptamer selection has been developed to obtain new probes in one working day. ${ }^{115}$ In parallel, the engineering of a novel class of proteins based on single-domain antibody fragments (nanobodies) also offers promising novel probes in the coming years. Their specificity is equal to the antibody's in addition to be being smaller in size, more chemically stable, and therefore easier to handle. ${ }^{116}$ The numerous detection and isolation methods shown in this review demonstrate that technology is up to the challenge of biosensing of EVs. However, commercial biosensors need to be portable, lowcost and easy to use. Miniaturization of such devices will be a major technological challenge in this research field. ${ }^{117}$ The exponential growth in the number of publications on biosensing of EVs since 2010 demonstrates that EVs have a significant potential as biomarkers for disease diagnosis. This potential is further reinforced by the availability of EVs in many biological fluids such as blood and urine.

Analyses of single EVs has also been demonstrated ${ }^{118,119}$ revealing variation in EV profiling that could not be accessed before given the inherent limits of heterogeneous samples assays. Moreover, a recent study has applied the field of single-cell studies to $E V s, 120$ thus opening a new window into single-cell secretion analysis. At the same time, accessing both information contained on the EV surface and inside EVs in the same biosensor is challenging to implement and only very few devices have been reported. ${ }^{28,43,45,121}$ While it is precisely this type of biosensors that physicians and clinicians need in medical institutions to establish diagnosis from blood or urine samples. Although juggling samples as complex as blood can be difficult, cell-depleted urine seems to be an attractive alternative, both of which will likely provide avenues for interesting research in the years to come.

\section{Acknowledgements}

This work has been supported by the French Laboratory of Excellence ANR program Labex ARCANE and CBH-EUR-GS (ANR-17-EURE-0003) for PhD funding, and by the FET Proactive H2020 Viruscan project (N731868). The authors would also like to thank Larry O'Connell and Pascal Colosetti for their help with the manuscript preparation.

\section{References}

$1 \quad$ M. Tkach and C. Théry, Cell, 2016, 164, 1226-1232.

2 G. van Niel, G. D'Angelo and G. Raposo, Nat Rev Mol Cell Biol, 2018, 19, 213-228. 
3 D. K. Jeppesen, A. M. Fenix, J. L. Franklin, J. N. Higginbotham, Q. Zhang, L. J. Zimmerman, D. C. Liebler, J. Ping, Q. Liu, R. Evans, W. H. Fissell, J. G. Patton, L. H. Rome, D. T. Burnette and R. J. Coffey, Cell, 2019, 177, 428-445.e18.

$4 \quad$ P. Wolf, British Journal of Haematology, 1967, 13, 269-288.

$5 \quad$ N. Crawford, British Journal of Haematology, 1971, 21, 53-69.

6 M. Yáñez-Mó, P. R. M. Siljander, Z. Andreu, A. Bedina Zavec, F. E. Borràs, E. I. Buzas, K. Buzas, E. Casal, F. Cappello, J. Carvalho, E. Colas, A. Cordeiro-da Silva, S. Fais, J. M. Falcon-Perez, I. M. Ghobrial, B. Giebel, M. Gimona, M. Graner, I. Gursel, M. Gursel, N. H. H. Heegaard, A. Hendrix, P. Kierulf, K. Kokubun, M. Kosanovic, V. Kralj-Iglic, E.-M. Krämer-Albers, S. Laitinen, C. Lässer, T. Lener, E. Ligeti, A. Linē, G. Lipps, A. Llorente, J. Lötvall, M. Manček-Keber, A. Marcilla, M. Mittelbrunn, I. Nazarenko, E. N. M. Nolte-'t Hoen, T. A. Nyman, L. O'Driscoll, M. Olivan, C. Oliveira, É. Pállinger, H. A. del Portillo, J. Reventos, M. Rigau, E. Rohde, M. Sammar, F. Sánchez-Madrid, N. Santarém, K. Schallmoser, M. Stampe Ostenfeld, W. Stoorvogel, R. Stukelj, S. G. Van der Grein, M. Helena Vasconcelos, M. H. M. Wauben and O. De Wever, Journal of Extracellular Vesicles, 2015, 4, 2706662.

$7 \quad$ S. Rome, Food Funct., 2019, 10, 529-538.

8 M. Colombo, G. Raposo and C. Théry, Annu. Rev. Cell Dev. Biol., 2014, 30, 255-289.

9 J. Kowal, M. Tkach and C. Théry, Current Opinion in Cell Biology, 2014, 29, 116-125.

10 D.-S. Choi, D.-K. Kim, Y.-K. Kim and Y. S. Gho, Proteomics, 2013, 13, 1554-1571.

11 S. Runz, S. Keller, C. Rupp, A. Stoeck, Y. Issa, D. Koensgen, A. Mustea, J. Sehouli, G. Kristiansen and P. Altevogt, Gynecologic Oncology, 2007, 107, 563-571.

12 J. Baran, M. Baj-Krzyworzeka, K. Weglarczyk, R. Szatanek, M. Zembala, J. Barbasz, A. Czupryna, A. Szczepanik and M. Zembala, Cancer Immunol Immunother, 2009, 59, 841-850.

13 V. Ciravolo, V. Huber, G. C. Ghedini, E. Venturelli, F. Bianchi, M. Campiglio, D. Morelli, A. Villa, P. D. Mina, S. Menard, P. Filipazzi, L. Rivoltini, E. Tagliabue and S. M. Pupa, J. Cell. Physiol., 2011, 227, 658-667.

14 M. P. Zaborowski, K. Lee, Y. J. Na, A. Sammarco, X. Zhang, M. Iwanicki, P. S. Cheah, H.-Y. Lin, M. Zinter, C.-Y. Chou, G. Fulci, B. A. Tannous, C. P.-K. Lai, M. J. Birrer, R. Weissleder, H. Lee and X. O. Breakefield, CellReports, 2019, 27, 255-268.e6.

15 R. Kalluri, Journal of Clinical Investigation, 2016, 126, 1208-1215.

16 A. Becker, B. K. Thakur, J. M. Weiss, H. S. Kim, H. Peinado and D. Lyden, Cancer Cell, 2016, 30, 836-848.

17 E. Reátegui, K. E. van der Vos, C. P. Lai, M. Zeinali, N. A. Atai, B. Aldikacti, F. P. Floyd, A. H Khankhel, V. Thapar, F. H. Hochberg, L. V. Sequist, B. V. Nahed, B. S Carter, M. Toner, L. Balaj, D. T Ting, X. O. Breakefield and S. L. Stott, Nature Communications, 2018, 9, 175-11.

18 Z. Zhao, J. Fan, Y.-M. S. Hsu, C. J. Lyon, B. Ning and T. Y. Hu, Lab Chip, 2019, 19, 1114-1140.

19 J. Lötvall, A. F. Hill, F. Hochberg, E. I. Buzas, D. Di Vizio, C. Gardiner, Y. S. Gho, I. V. Kurochkin, S. Mathivanan, P. Quesenberry, S. Sahoo, H. Tahara, M. H. Wauben, K. W. Witwer and C. Théry, Journal of Extracellular Vesicles, 2014, 3, 26913-6. 
20 C. Théry, K. W. Witwer, E. Aikawa, M. J. Alcaraz, J. D. Anderson, R. Andriantsitohaina, A. Antoniou, T. Arab, F. Archer, G. K. Atkin-Smith, D. C. Ayre, J.-M. Bach, D. Bachurski, H. Baharvand, L. Balaj, S. Baldacchino, N. N. Bauer, A. A. Baxter, M. Bebawy, C. Beckham, A. B. Zavec, A. Benmoussa, A. C. Berardi, P. Bergese, E. Bielska, C. Blenkiron, S. Bobis-Wozowicz, E. Boilard, W. Boireau, A. Bongiovanni, F. E. Borràs, S. Bosch, C. M. Boulanger, X. Breakefield, A. M. Breglio, M. A. Brennan, D. R. Brigstock, A. Brisson, M. L. Broekman, J. F. Bromberg, P. BrylGórecka, S. Buch, A. H. Buck, D. Burger, S. Busatto, D. Buschmann, B. Bussolati, E. I. Buzas, J. B. Byrd, G. Camussi, D. R. Carter, S. Caruso, L. W. Chamley, Y.-T. Chang, A. D. Chaudhuri, C. Chen, S. Chen, L. Cheng, A. R. Chin, A. Clayton, S. P. Clerici, A. Cocks, E. Cocucci, R. J. Coffey, A. Cordeiro-da Silva, Y. Couch, F. A. Coumans, B. Coyle, R. Crescitelli, M. F. Criado, C. D'Souza-Schorey, S. Das, P. de Candia, E. F. De Santana, O. De Wever, H. A. del Portillo, T. Demaret, S. Deville, A. Devitt, B. Dhondt, D. Di Vizio, L. C. Dieterich, V. Dolo, A. P. D. Rubio, M. Dominici, M. R. Dourado, T. A. Driedonks, F. V. Duarte, H. M. Duncan, R. M. Eichenberger, K. Ekström, S. E. Andaloussi, C. Elie-Caille, U. Erdbrügger, J. M. Falcon-Perez, F. Fatima, J. E. Fish, M. Flores-Bellver, A. Försönits, A. Frelet-Barrand, F. Fricke, G. Fuhrmann, S. Gabrielsson, A. Gámez-Valero, C. Gardiner, K. Gärtner, R. Gaudin, Y. S. Gho, B. Giebel, C. Gilbert, M. Gimona, I. Giusti, D. C. Goberdhan, A. Görgens, S. M. Gorski, D. W. Greening, J. C. Gross, A. Gualerzi, G. N. Gupta, D. Gustafson, A. Handberg, R. A. Haraszti, P. Harrison, H. Hegyesi, A. Hendrix, A. F. Hill, F. H. Hochberg, K. F. Hoffmann, B. Holder, H. Holthofer, B. Hosseinkhani, G. Hu, Y. Huang, V. Huber, S. Hunt, A. G.-E. Ibrahim, T. Ikezu, J. M. Inal, M. Isin, A. Ivanova, H. K. Jackson, S. Jacobsen, S. M. Jay, M. Jayachandran, G. Jenster, L. Jiang, S. M. Johnson, J. C. Jones, A. Jong, T. Jovanovic-Talisman, S. Jung, R. Kalluri, S.-I. Kano, S. Kaur, Y. Kawamura, E. T. Keller, D. Khamari, E. Khomyakova, A. Khvorova, P. Kierulf, K. P. Kim, T. Kislinger, M. Klingeborn, D. J. Klinke, M. Kornek, M. M. Kosanović, Á. F. Kovács, E.-M. Krämer-Albers, S. Krasemann, M. Krause, I. V. Kurochkin, G. D. Kusuma, S. Kuypers, S. Laitinen, S. M. Langevin, L. R. Languino, J. Lannigan, C. Lässer, L. C. Laurent, G. Lavieu, E. Lázaro-Ibáñez, S. Le Lay, M.-S. Lee, Y. X. F. Lee, D. S. Lemos, M. Lenassi, A. Leszczynska, I. T. Li, K. Liao, S. F. Libregts, E. Ligeti, R. Lim, S. K. Lim, A. Linē, K. Linnemannstöns, A. Llorente, C. A. Lombard, M. J. Lorenowicz, Á. M. Lörincz, J. Lötvall, J. Lovett, M. C. Lowry, X. Loyer, Q. Lu, B. Lukomska, T. R. Lunavat, S. L. Maas, H. Malhi, A. Marcilla, J. Mariani, J. Mariscal, E. S. Martens-Uzunova, L. Martin-Jaular, M. C. Martinez, V. R. Martins, M. Mathieu, S. Mathivanan, M. Maugeri, L. K. McGinnis, M. J. McVey, D. G. Meckes, K. L. Meehan, I. Mertens, V. R. Minciacchi, A. Möller, M. M. Jørgensen, A. Morales-Kastresana, J. Morhayim, F. Mullier, M. Muraca, L. Musante, V. Mussack, D. C. Muth, K. H. Myburgh, T. Najrana, M. Nawaz, I. Nazarenko, P. Nejsum, C. Neri, T. Neri, R. Nieuwland, L. Nimrichter, J. P. Nolan, E. N. N.-'. Hoen, N. N. Hooten, L. O'Driscoll, T. O'Grady, A. O'Loghlen, T. Ochiya, M. Olivier, A. Ortiz, L. A. Ortiz, X. Osteikoetxea, O. Ostegaard, M. Ostrowski, J. Park, D. M. Pegtel, H. Peinado, F. Perut, M. W. Pfaffl, D. G. Phinney, B. C. Pieters, R. C. Pink, D. S. Pisetsky, E. P. von Strandmann, I. Polakovicova, I. K. Poon, B. H. Powell, I. Prada, 
L. Pulliam, P. Quesenberry, A. Radeghieri, R. L. Raffai, S. Raimondo, J. Rak, M. I. Ramirez, G. Raposo, M. S. Rayyan, N. Regev-Rudzki, F. L. Ricklefs, P. D. Robbins, D. D. Roberts, S. C. Rodrigues, E. Rohde, S. Rome, K. M. Rouschop, A. Rughetti, A. E. Russell, P. Saá, S. Sahoo, E. Salas-Huenuleo, C. Sánchez, J. A. Saugstad, M. J. Saul, R. M. Schiffelers, R. Schneider, T. H. Schøyen, A. Scott, E. Shahaj, S. Sharma, O. Shatnyeva, F. Shekari, G. V. Shelke, A. K. Shetty, K. Shiba, P. R. M. Siljander, A. M. Silva, A. Skowronek, O. L. Snyder, R. P. Soares, B. W. Sódar, C. Soekmadji, J. Sotillo, P. D. Stahl, W. Stoorvogel, S. L. Stott, E. F. Strasser, S. Swift, H. Tahara, M. Tewari, K. Timms, S. Tiwari, R. Tixeira, M. Tkach, W. S. Toh, R. Tomasini, A. C. Torrecilhas, J. P. Tosar, V. Toxavidis, L. Urbanelli, P. Vader, B. W. van Balkom, S. G. Van der Grein, J. Van Deun, M. J. van Herwijnen, K. Van Keuren-Jensen, G. van Niel, M. E. van Royen, A. J. van Wijnen, M. H. Vasconcelos, I. J. Vechetti, T. D. Veit, L. J. Vella, É. Velot, F. J. Verweij, B. Vestad, J. L. Viñas, T. Visnovitz, K. V. Vukman, J. Wahlgren, D. C. Watson, M. H. Wauben, A. Weaver, J. P. Webber, V. Weber, A. M. Wehman, D. J. Weiss, J. A. Welsh, S. Wendt, A. M. Wheelock, Z. Wiener, L. Witte, J. Wolfram, A. Xagorari, P. Xander, J. Xu, X. Yan, M. Yáñez-Mó, H. Yin, Y. Yuana, V. Zappulli, J. Zarubova, V. Žèkas, J.-Y. Zhang, Z. Zhao, L. Zheng, A. R. Zheutlin, A. M. Zickler, P. Zimmermann, A. M. Zivkovic, D. Zocco and E. K. Zuba-Surma, Journal of Extracellular Vesicles, 2018, 7, 1-47.

21 C. Théry, S. Amigorena, G. Raposo and A. Clayton, Current Protocols in Cell Biology, 2006, 30, 3.22.1-3.22.29.

22 S. A. Melo, L. B. Luecke, C. Kahlert, A. F. Fernandez, S. T. Gammon, J. Kaye, V. S. LeBleu, E. A. Mittendorf, J. Weitz, N. Rahbari, C. Reissfelder, C. Pilarsky, M. F. Fraga, D. Piwnica-Worms and R. Kalluri, Nature, 2015, 523, 177-182.

23 J. Ko, N. Bhagwat, T. Black, S. S. Yee, Y. J. Na, S. Fisher, J. Kim, E. L. Carpenter, B. Z. Stanger and D. Issadore, Cancer Research, 2018, 78, 3688-3697.

24 N. Karimi, A. Cvjetkovic, S. C. Jang, R. Crescitelli, M. A. H. Feizi, R. Nieuwland, J. Lötvall and C. Lässer, Cellular and Molecular Life Sciences, 2018, 75, 2873-2886.

25 R. J. Lobb, M. Becker, S. Wen Wen, C. S. F. Wong, A. P. Wiegmans, A. Leimgruber and A. Möller, Journal of Extracellular Vesicles, 2015, 4, 27031-12.

26 L. Paolini, A. Zendrini, G. D. Noto, S. Busatto, E. Lottini, A. Radeghieri, A. Dossi, A. Caneschi, D. Ricotta and P. Bergese, Sci. Rep., 2016, 6, 373.

27 J. Ko, E. Carpenter and D. Issadore, Analyst, 2016, 141, 450-460.

28 C. Chen, J. Skog, C.-H. Hsu, R. T. Lessard, L. Balaj, T. Wurdinger, B. S. Carter, X. O. Breakefield, M. Toner and D. Irimia, Lab Chip, 2010, 10, 505-511.

29 S. S. Kanwar, C. J. Dunlay, D. M. Simeone and S. Nagrath, Lab Chip, 2014, 14, 18911900.

30 J. T. Smith, B. H. Wunsch, N. Dogra, M. E. Ahsen, K. Lee, K. K. Yadav, R. Weil, M. A. Pereira, J. V. Patel, E. A. Duch, J. M. Papalia, M. F. Lofaro, M. Gupta, A. K. Tewari, C. Cordon-Cardo, G. Stolovitzky and S. M. Gifford, Lab Chip, 2018, 18, 3913-3925.

31 B. H. Wunsch, J. T. Smith, S. M. Gifford, C. Wang, M. Brink, R. L. Bruce, R. H. Austin, G. Stolovitzky and Y. Astier, Nature Nanotechnology, 2016, 11, 936-940.

32 R. T. Davies, J. Kim, S. C. Jang, E.-J. Choi, Y. S. Gho and J. Park, Lab Chip, 2012, 12, $5202-9$. 
33 J. C. Contreras-Naranjo, H. J. Wu and V. M. Ugaz, Lab Chip, 2017, 17, 3558-3577.

34 V. Palanisamy, S. Sharma, A. Deshpande, H. Zhou, J. Gimzewski and D. T. Wong, PLoS ONE, 2010, 5, e8577-11.

35 J.-L. Fraikin, T. Teesalu, C. M. Mckenney, E. Ruoslahti and A. N. Cleland, Nature Nanotechnology, 2011, 6, 308-313.

36 S. Olcum, N. Cermak, S. C. Wasserman, K. S. Christine, H. Atsumi, K. R. Payer, W. Shen, J. Lee, A. M. Belcher, S. N. Bhatia and S. R. Manalis, Proceedings of the National Academy of Sciences of the United States of America, 2014, 111, 1310-1315.

37 S. Keerthikumar, D. Chisanga, D. Ariyaratne, H. Al Saffar, S. Anand, K. Zhao, M. Samuel, M. Pathan, M. Jois, N. Chilamkurti, L. Gangoda and S. Mathivanan, J Mol Biol, 2016, 428, 688-692.

38 C. Thery, L. Zitvogel and S. Amigorena, Nat Rev Immunol, 2002, 2, 569-579.

39 E. Pariset, V. Agache and A. Millet, Advanced Biosystems, 2017, 1, 1700040-12.

40 C. L. Hisey, K. D. P. Dorayappan, D. E. Cohn, K. Selvendiran and D. J. Hansford, Lab Chip, 2018, 18, 3144-3153.

41 R. Qi, G. Zhu, Y. Wang, S. Wu, S. Li, D. Zhang, Y. Bu, G. Bhave, R. Han and X. Liu, Biomed Microdevices, 2019, 21, 4363.

42 Y. Wang, W. Yuan, M. Kimber, M. Lu and L. Dong, ACS Sens., 2018, 3, 1616-1621.

43 H. Shao, J. Chung, K. Lee, L. Balaj, C. Min, B. S. Carter, F. H. Hochberg, X. O. Breakefield, H. Lee and R. Weissleder, Nature Communications, 2015, 6, 1-9.

44 J. S. Dudani, D. R. Gossett, H. T. K. Tse, R. J. Lamm, R. P. Kulkarni and D. D. Carlo, Biomicrofluidics, 2015, 9, 014112-9.

45

46

47

48

49

50

51

52

53

54

55

M. He, J. Crow, M. Roth, Y. Zeng and A. K. Godwin, Lab Chip, 2014, 14, 3773-3780. S. Kumar, J. A. Han, I. J. Michael, D. Ki, V. Sunkara, J. Park, S. Gautam, H. K. Ha, L. Zhang and Y. K. Cho, Adv. Funct. Mater., 2019, 29, 1902669-7.

L. Zhu, K. Wang, J. Cui, H. Liu, X. Bu, H. Ma, W. Wang, H. Gong, C. Lausted, L. Hood, G. Yang and Z. Hu, Anal Chem, 2014, 86, 8857-8864.

B. Hosseinkhani, N. van den Akker, J. D'Haen, M. Gagliardi, T. Struys, I. Lambrichts, J. Waltenberger, I. Nelissen, J. Hooyberghs, D. G. M. Molin and L. Michiels, Nanomedicine: Nanotechnology, Biology, and Medicine, 2017, 13, 1663-1671.

G. Qiu, A. Thakur, C. Xu, S.-P. Ng, Y. Lee and C.-M. L. Wu, Adv. Funct. Mater., 2019, 29, 1806761.

50 X. Zeng, Y. Yang, N. Zhang, D. Ji, X. Gu, J. Jornet, Y. Wu and Q. Gan, IEEE J Sel Top Quantum Electron, 2019, 25.

1 A. T. Reiner, N.-G. Ferrer, P. Venugopalan, R. C. Lai, S. K. Lim and J. Dostálek, Analyst, 2017, 142, 3913-3921.

2 Q. Wang, L. Zou, X. Yang, X. Liu, W. Nie, Y. Zheng, Q. Cheng and K. Wang, Biosensors and Bioelectronics, 2019, 135, 129-136.

3 K. Liang, F. Liu, J. Fan, D. Sun, C. Liu, C. J. Lyon, D. W. Bernard, Y. Li, K. Yokoi, M. H. Katz, E. J. Koay, Z. Zhao and Y. Hu, Nat Biomed Eng, 2017, 1, 659-11.

4 H. F. G. Heijnen, A. E. Schiel, R. Fijnheer, H. J. Geuze and J. J. Sixma, Blood, 1999, 94, 3791-3799.

C. Lässer, M. Eldh and J. Lötvall, JoVE, 2012, 1-6. 
56 N. Koliha, Y. Wiencek, U. Heider, C. Jüngst, N. Kladt, S. Krauthäuser, I. C. D. Johnston, A. Bosio, A. Schauss and S. Wild, Journal of Extracellular Vesicles, 2016, 5, 29975-16.

57 R. P. Carney, S. Hazari, M. Colquhoun, D. Tran, B. Hwang, M. S. Mulligan, J. D. Bryers, E. Girda, G. S. Leiserowitz, Z. J. Smith and K. S. Lam, Anal Chem, 2017, 89, 5357-5363.

58 P. Beekman, A. Enciso-Martinez, H. S. Rho, S. P. Pujari, A. Lenferink, H. Zuilhof, L. W. M. M. Terstappen, C. Otto and S. Le Gac, Lab Chip, 2019, 2, 72-11.

59 Y.-F. Tian, C.-F. Ning, F. He, B.-C. Yin and B.-C. Ye, Analyst, 2018, 143, 4915-4922.

60 G. G. Daaboul, P. Gagni, L. Benussi, P. Bettotti, M. Ciani, M. Cretich, D. S. Freedman, R. Ghidoni, A. Y. Ozkumur, C. Piotto, D. Prosperi, B. Santini, M. S. Ünlü and M. Chiari, Scientific Reports, 2016, 6, 37246.

61 L. C. Clark and C. Lyons, Ann. N. Y. Acad. Sci., 1962, 102, 29-45.

62 K. Boriachek, M. N. Islam, V. Gopalan, A. K. Lam, N. T. Nguyen and M. J. A. Shiddiky, Analyst, 2017, 142, 2211-2219.

63 T. Kilic, A. T. D. S. Valinhas, I. Wall, P. Renaud and S. Carrara, Sci. Rep., 2018, 8, 347.

64 X. Doldán, P. Fagúndez, A. Cayota, J. Laíz and J. P. Tosar, Anal Chem, 2016, 88, 10466-10473.

65 S. Cavallaro, J. Horak, P. Hååg, D. Gupta, C. Stiller, S. S. Sahu, A. Görgens, H. K. Gatty, K. Viktorsson, S. El Andaloussi, R. Lewensohn, A. E. Karlström, J. Linnros and A. Dev, ACS Sens., 2019, 4, 1399-1408.

66 Z. Andreu and M. Yáñez-Mó, Frontiers in Immunology, 2014, 5.

67 M. Oliveira-Rodríguez, S. López-Cobo, H. T. Reyburn, A. Costa-García, S. LópezMartín, M. Yáñez-Mó, E. Cernuda-Morollón, A. Paschen, M. Valés-Gómez and M. C. Blanco-López, Journal of Extracellular Vesicles, 2016, 5, 31803.

68 C. Tuerk and L. Gold, Science, 1990, 249, 505-510.

69 A. D. Ellington and J. W. Szostak, Nature, 1990, 346, 818-822.

70 Q. Zhou, A. Rahimian, K. Son, D.-S. Shin, T. Patel and A. Revzin, Methods, 2016, 97, 88-93.

71 H. Zhang, Z. Wang, Q. Zhang, F. Wang and Y. Liu, Biosensors and Bioelectronic, 2019, 124-125, 184-190.

72 Y. Xia, M. Liu, L. Wang, A. Yan, W. He, M. Chen, J. Lan, J. Xu, L. Guan and J. Chen, Biosensors and Bioelectronic, 2017, 92, 8-15.

73 Z. Zhang, C. Tang, L. Zhao, L. Xu, W. Zhou, Z. Dong, Y. Yang, Q. Xie and X. Fang, Nanoscale, 2019, 11, 10106-10113.

74 X. Dong, J. Chi, L. Zheng, B. Ma, Z. Li, S. Wang, C. Zhao and H. Liu, Lab Chip, 2019, 19, 2897-2904.

75 X. Chen, J. Lan, Y. Liu, L. Li, L. Yan, Y. Xia, F. Wu, C. Li, S. Li and J. Chen, Biosensors and Bioelectronic, 2018, 102, 582-588.

76 Q. Zhang, F. Wang, H. Zhang, Y. Zhang, M. Liu and Y. Liu, Anal Chem, 2018, 90, 12737-12744.

77 Y. Lyu, D. Cui, J. Huang, W. Fan, Y. Miao and K. Pu, Angew. Chem. Int. Ed., 2019, 58, 4983-4987. 
78 J. Zhang, J. Shi, W. Liu, K. Zhang, H. Zhao, H. Zhang and Z. Zhang, Sensors \& Actuators: B. Chemical, 2018, 276, 552-559.

79 H. Wang, H. Chen, Z. Huang, T. Li, A. Deng and J. Kong, Talanta, 2018, 184, 219 226.

80 D. Jin, F. Yang, Y. Zhang, L. Liu, Y. Zhou, F. Wang and G.-J. Zhang, Anal Chem, 2018, 90, 14402-14411.

81 X. Yu, L. He, M. Pentok, H. Yang, Y. Yang, Z. Li, N. He, Y. Deng, S. Li, T. Liu, X. Chen and H. Luo, Nanoscale, 2019, 11, 15589-15595.

82 F. He, H. Liu, X. Guo, B.-C. Yin and B.-C. Ye, Anal Chem, 2017, 89, 12968-12975.

83 F. He, J. Wang, B.-C. Yin and B.-C. Ye, Anal Chem, 2018, 90, 8072-8079.

84 H. Dong, H. Chen, J. Jiang, H. Zhang, C. Cai and Q. Shen, Anal Chem, 2018, 90, 45074513.

85 Y. Jiang, M. Shi, Y. Liu, S. Wan, C. Cui, L. Zhang and W. Tan, Angew. Chem. Int. Ed., 2017, 56, 11916-11920.

86 Z. Wang, S. Zong, Y. Wang, N. Li, L. Li, J. Lu, Z. Wang, B. Chen and Y. Cui, Nanoscale, 2018, 10, 9053-9062.

87 J. Chen, Y. Xu, Y. Lu and W. Xing, Anal Chem, 2018, 90, 14207-14215.

88 K. Zhang, Y. Yue, S. Wu, W. Liu, J. Shi and Z. Zhang, ACS Sens., 2019, 4, 1245-1251.

89 M.-L. Gao, F. He, B.-C. Yin and B.-C. Ye, Analyst, 2019, 144, 1995-2002.

90 C. Liu, J. Zhao, F. Tian, J. Chang, W. Zhang and J. Sun, J Am Chem Soc, 2019, 141, 3817-3821.

91 Q. Tian, C. He, G. Liu, Y. Zhao, L. Hui, Y. Mu, R. Tang, Y. Luo, S. Zheng and Ben Wang, Anal Chem, 2018, 90, 6556-6562.

92 D. He, S.-L. Ho, H.-N. Chan, H. Wang, L. Hai, X. He, K. Wang and H.-W. Li, Anal Chem, 2019, 91, 2768-2775.

93 W. Liu, J. Li, Y. Wu, S. Xing, Y. Lai and G. Zhang, Biosensors and Bioelectronic, 2018, 102, 204-210.

94 L. Huang, D.-B. Wang, N. Singh, F. Yang, N. Gu and X.-E. Zhang, Nanoscale, 2018, 10, 20289-20295.

95 S.-L. Hong, Y.-T. Wan, M. Tang, D.-W. Pang and Z.-L. Zhang, Anal Chem, 2017, 89, 6535-6542.

96 S. Wang, L. Zhang, S. Wan, S. Cansiz, C. Cui, Y. Liu, R. Cai, C. Hong, I.-T. Teng, M. Shi, Y. Wu, Y. Dong and W. Tan, Acs Nano, 2017, 11, 3943-3949.

97 D. L. McMinn, A. K. Ogawa, Y. Wu, J. Liu, P. G. Schultz and F. E. Romesberg, J Am Chem Soc, 1999, 121, 11585-11586.

98 V. Domenyuk, Z. Zhong, A. Stark, N. Xiao, H. A. O'Neill, X. Wei, J. Wang, T. T. Tinder, S. Tonapi, J. Duncan, T. Hornung, A. Hunter, M. R. Miglarese, J. Schorr, D. D. Halbert, J. Quackenbush, G. Poste, D. A. Berry, G. Mayer, M. Famulok and D. Spetzler, Nature Publishing Group, 2017, 7, 42741.

99 R. Behrendt, P. White and J. Offer, J. Pept. Sci., 2016, 22, 4-27.

100 R. Tamura and H. Yin, Adv Clin Chem, 2017, 79, 25-41.

101 S. E. Andaloussi, I. Mäger, X. O. Breakefield and M. J. A. Wood, Nat Rev Drug Discov, 2013, 12, 347-357. 
102 L. A. Morton, H. Yang, J. P. Saludes, Z. Fiorini, L. Beninson, E. R. Chapman, M. Fleshner, D. Xue and H. Yin, ACS Chem. Biol., 2013, 8, 218-225.

103 J. P. Saludes, L. A. Morton, N. Ghosh, L. A. Beninson, E. R. Chapman, M. Fleshner and H. Yin, ACS Chem. Biol., 2012, 7, 1629-1635.

104 J. P. Saludes, L. A. Morton, S. K. Coulup, Z. Fiorini, B. M. Cook, L. Beninson, E. R. Chapman, M. Fleshner and H. Yin, Mol. BioSyst., 2013, 9, 2005-6.

105 A. Ghosh, M. Davey, I. C. Chute, S. G. Griffiths, S. Lewis, S. Chacko, D. Barnett, N. Crapoulet, S. Fournier, A. Joy, M. C. Caissie, A. D. Ferguson, M. Daigle, M. V. Meli, S. M. Lewis and R. J. Ouellette, PLoS ONE, 2014, 9, e110443-12.

106 J. C. Knol, I. de Reus, T. Schelfhorst, R. Beekhof, M. de Wit, S. R. Piersma, T. V. Pham, E. F. Smit, H. M. W. Verheul and C. R. Jimenez, EuPA Open Proteom, 2016, 11, 11-15.

107 I. V. Bijnsdorp, O. Maxouri, A. Kardar, T. Schelfhorst, S. R. Piersma, T. V. Pham, A. Vis, R. J. van Moorselaar and C. R. Jimenez, Journal of Extracellular Vesicles, 2017, 6, $1-10$.

108 A. P. Joy, D. C. Ayre, I. C. Chute, A.-P. Beauregard, G. Wajnberg, A. Ghosh, S. M. Lewis, R. J. Ouellette and D. A. Barnett, Journal of Extracellular Vesicles, 2018, 7, 1-13.

109 R. Friedrich, S. Block, M. Alizadehheidari, S. Heider, J. Fritzsche, E. K. Esbjörner, F. Westerlund and M. Bally, Lab Chip, 2017, 17, 830-841.

110 P. E. G. Thorén, D. Persson, P. Isakson, M. Goksör, A. Önfelt and B. Nordén, Biochemical and Biophysical Research Communications, 2003, 307, 100-107.

111 M. Yoshida, K. Hibino, S. Yamamoto, S. Matsumura, Y. Yajima and K. Shiba, Biotechnol. Bioeng., 2017, 115, 536-544.

112 C. Lee, R. Carney, K. Lam and J. W. Chan, J Raman Spectrosc, 2017, 48, 1771-1776.

113 R. Stoltenburg, C. Reinemann and B. Strehlitz, Biomolecular Engineering, 2007, 24, 381-403.

114 N. N. Quang, A. Miodek, A. Cibiel and F. Ducongé, Methods Mol. Biol., 2017, 1575, 253-272.

115 S. Lisi, E. Fiore, S. Scarano, E. Pascale, Y. Boehman, F. Ducongé, S. Chierici, M. Minunni, E. Peyrin and C. Ravelet, Analytica Chimica Acta, 2018, 1038, 173-181.

116 T. De Meyer, S. Muyldermans and A. Depicker, Trends in Biotechnology, 2014, 32, 263-270.

117 E. B. Bahadır and M. K. Sezgintürk, Anal Biochem, 2015, 478, 107-120.

118 Z. J. Smith, C. Lee, T. Rojalin, R. P. Carney, S. Hazari, A. Knudson, K. Lam, H. Saari, E. L. Ibañez, T. Viitala, T. Laaksonen, M. Yliperttula and S. Wachsmann-Hogiu, Journal of Extracellular Vesicles, 2015, 4, 28533-16.

119 K. Lee, K. Fraser, B. Ghaddar, K. Yang, E. Kim, L. Balaj, E. A. Chiocca, X. O. Breakefield, H. Lee and R. Weissleder, Acs Nano, 2018, 12, 494-503.

120 Y. Ji, D. Qi, L. Li, H. Su, X. Li, Y. Luo, B. Sun, F. Zhang, B. Lin, T. Liu and Y. Lu, Proc Natl Acad Sci USA, 2019, 116, 5979-5984.

121 X. Fang, Y. Duan, G. B. Adkins, S. Pan, H. Wang, Y. Liu and W. Zhong, Anal Chem, 2018, 90, 2787-2795. 